\title{
Detecting systemic change in a land use system by Bayesian data assimilation $^{\text {म2 }}$
}

\author{
Judith A. Verstegen ${ }^{\mathrm{a},}{ }^{*}$, Derek Karssenberg ${ }^{\mathrm{b}}$, Floor van der Hilst ${ }^{\mathrm{a}}$, André P.C. Faaij ${ }^{\mathrm{a}}$ \\ ${ }^{a}$ Copernicus Institute for Sustainable Development and Innovation, Faculty of Geosciences, Utrecht University, Heidelberglaan 2, 3584 CD Utrecht, \\ The Netherlands \\ ${ }^{\mathrm{b}}$ Department of Physical Geography, Faculty of Geosciences, Utrecht University, Heidelberglaan 2, PO Box 80115, 3508 TC Utrecht, The Netherlands
}

\section{A R T I C L E I N F O}

\section{Article history:}

Received 30 May 2013

Received in revised form

16 January 2015

Accepted 16 February 2015

Available online 10 March 2015

\section{Keywords}

Systemic change

Land use change

Stationarity

Data assimilation

Particle filter

Simulation

Spatial modelling

\begin{abstract}
A B S T R A C T
A spatially explicit land use change model is typically based on the assumption that the relationship between land use change and its explanatory processes is stationary. This means that model structure and parameterization are usually kept constant over the model runtime, ignoring potential systemic changes in this relationship resulting from societal changes. We have developed a methodology to test for systemic changes and demonstrate it by assessing whether or not a land use change model with a constant model structure is an adequate representation of the land use system given a time series of observations of past land use. This was done by assimilating observations of real land use into a land use change model, using a Bayesian data assimilation technique, the particle filter. The particle filter was used to update the prior knowledge about the model structure, i.e. the selection and relative importance of the explanatory processes for land use change allocation, and about the parameters. For each point in time for which observations were available the optimal model structure and parameterization were determined. In a case study of sugar cane expansion in Brazil, it was found that the assumption of a constant model structure was not fully adequate, indicating systemic change in the modelling period (2003-2012). The systemic change appeared to be indirect: a factor has an effect on the demand for sugar cane, an input variable, in such a way that the transition rules and parameters have to change as well. Although an inventory was made of societal changes in the study area during the studied period, none of them could be directly related to the onset of the observed systemic change in the land use system. Our method which allows for systemic changes in the model structure resulted in an average increase in the $95 \%$ confidence interval of the projected sugar cane fractions of a factor of two compared to the assumption of a stationary system. This shows the importance of taking into account systemic changes in projections of land use change in order not to underestimate the uncertainty of future projections.
\end{abstract}

๑) 2015 Elsevier Ltd. All rights reserved.

\section{Software/code availability}

Name PCRaster Python framework

freely downloadable at http://www.pcraster.eu

Contact d.karssenberg@uu.nl

Required software:

PCRaster Linux, OS X and Windows, GNU GPL v3, available at http://www.pcraster.eu

\footnotetext{
Thematic Issue on the Modelling Systemic Change.

* Corresponding author.

E-mail addresses: J.A.Verstegen@uu.nl, judithverstegen@gmail.com
} (J.A. Verstegen).
Python all major platforms, available at http://www. python.org

Name PCRaster Land Use Change model (PLUC)

Availability on request by contacting the author

Contact J.A.Verstegen@uu.nl

Required software:

PCRaster runs on Linux, OS X and Windows, GNU GPL v3, available at http://www.pcraster.eu

Python runs on all major platforms, available at http:// www.python.org 


\section{Introduction}

Land use change (LUC) is the result of complex interactions between socio-economic and environmental processes (Verburg, 2006; Brown et al., 2008). To simulate potential development pathways in the land use system, scenario storylines are used in combination with land use change models. Various modelling approaches have been designed for this. Several such approaches are founded on the conceptual distinction between 1) the quantity of change per land use type, also called demand, and 2) the spatial allocation of this change (Pontius and Neeti, 2010). The quantity of change can be seen as a model input, because it is dictated by the scenario storyline, and the spatial allocation of change is defined by the model structure and parameters. The model structure consists of a set of suitability factors that serve as proxies for the land use system being socio-economic and environmental processes that regulate the location of change (e.g., Verburg et al., 2002; van der Hilst et al., 2012; Schaldach et al., 2011), such as topography, accessibility, and potential revenues, and the way these factors interrelate.

Although there are some exceptions (e.g., Clarke et al., 1997; Carlson et al., 2012), the selection, relative importance and parameterization of the suitability factors, i.e. the model structure and its parameters, are in current applications usually kept constant over model runtime. A crucial assumption, implicit in this method, is that the relationship between LUC and its explanatory processes is stationary (Manson, 2007). This assumption ignores potential systemic changes in this relationship resulting from societal changes including technological, political or economic developments. A systemic change is a fundamental change in system structure. Because the notion of 'fundamental' is subjective, we recognize systemic change in the context of models by: "a system state change that cannot be simulated using a constant model structure and/or parameterization". This definition is further explained in Section 2.1. Our aim is to develop a general methodology, applicable to any type of model, to test for systemic change given this definition. We demonstrate this methodology in a case study with a land use change model and try to answer the following questions: 1) Is the assumption of a spatially explicit LUC model with a constant model structure and parameters, as generally used in the land use change community, an adequate representation of the land use system, or do observations of past land use over time indicate systemic changes? 2) If systemic changes occur, can these be related to known societal changes? 3) How does the inclusion of systemic changes in the model affect model projection uncertainty?

Evaluation of the stationarity of the relationship between land use and a set of spatial attributes has been done by others (Aspinall, 2004; Bakker et al., 2011; Bakker and Veldkamp, 2012). These studies use logistic regression, separately from the land use change model. Therefore, they do not gain information on how to implement the (either changing or constant) spatial attributes into the model, in other words, how to turn these attributes into suitability factors, which restricts their value for the challenge of modelling systemic change. In addition, they often do not take into account uncertainty in the model and/or observational data and compare only two points in time, with the exception of Bakker et al. (2011), who compare three points in time.

To overcome these restrictions, we assimilate a time series of observations of real land use into a spatially explicit LUC model to find the best model configuration for different points in time. A similar approach has been demonstrated in the field of hydrology by Merz et al. (2011). Here, we use the particle filter (van Leeuwen, 2009), which is a Bayesian estimation or data assimilation technique. A particle filter updates the prior knowledge about the model structure and parameters during model runtime at points in time for which observations are available. In this way we assess the land use system structure, or model structure, as a whole, instead of only its components independently, in a fashion similar to our previous study (Verstegen et al., 2014). Unlike in this previous study, we apply the particle filter here separately for each year for which a land use map is available. By following this approach, optimal model structures and parameterizations can be obtained for these different points in time. This allows us to create a time series of the evolution of the model structure and parameters. Two stationarity tests, a distribution comparison test and the Runs test (Wald and Wolfowitz, 1940), are used to assess deviations in this time series and to check whether these deviations can be attributed to randomness or not. If not, this indicates systemic change. An important advantage of the particle filter compared to, for example, logistic regression is that it provides posterior knowledge including uncertainty, which enables providing confidence intervals for the identified model structures and the associated land use change projections.

We have set up a spatially explicit land use change model simulating sugar cane cropland expansion in the state of São Paulo in Brazil for the period 2003 to 2012, for which a time series of sugar cane occurrence maps of high quality (Rudorff et al., 2010; Adami et al., 2012a) is available as observational data. This case is suitable for testing our approach, because there are a number of societal changes in Brazil in the studied period that might have caused systemic change in the sugar cane expansion patterns, e.g., the economic crisis in 2008, and the adaptation of the Forest Code in 2012 . We consider four suitability factors that could potentially be of importance in the spatial allocation of new sugar cane fields: sugar cane in the neighbourhood, distance to the sugar cane processing mills, potential yield, and slope. First, we use a synthetic dataset generated by the model for the years 2004-2012 and demonstrate that the particle filter can reproduce the model structure and parameters which were applied to generate this synthetic dataset. Second, we use the real observations as observational data, to find the best fitting model structure and parameters for the real system for each of the years. Significant variations in optimal model structure and parameters between consecutive years would indicate that the changes in these years cannot be simulated using the stationarity assumption, and therefore signify systemic changes. In our study we try to relate the changes in model structure over time to the societal changes identified beforehand.

Next, sugar cane expansion is projected for the years 2013-2022. For this projection phase, the model is run with model structure and parameters varying over time. The trend in this variation, if any, depends on the connection between societal changes and the variation in model structure and parameters found for the time span between 2004 and 2012. This run is compared to a run with a classical model having a constant model structure and parameters. Differences in system state behaviour and uncertainty are evaluated.

The next section explores the concept of systemic change in the context of models, and provides explanations of the land use change model, the particle filter technique, and the stationarity analysis. Section 3 describes the case study, mentions potential causes of systemic changes in the case study area, and delineates the different model runs. Section 4, and 5 and 6 are the results, discussion, and conclusion sections.

\section{Methods}

2.1. Systemic change

In the introduction, systemic change was defined as a change in the system indicated by a system state change that cannot be simulated using a constant model 
structure and/or parameterization. The system state as a function of the model structure can be described as:

$\mathbf{y}_{t}=\mathbf{f}\left(\mathbf{y}_{t-1}, \mathbf{x}_{t}, \mathbf{p}\right)$, for each $t=1,2, \ldots, T$

In Equation (1), $\mathbf{y}_{t}$ is the system state at the time step $t, \mathbf{f}$ is the set of transition rules, representing the processes that lead to change in the system state over time, and the way they are implemented and combined, i.e. the model structure. The vector $\mathbf{x}_{t}$ represents all inputs, both spatial and non-spatial, and $\mathbf{p}$ contains the parameters of the transition rules $\mathbf{f}$. In the case of a spatially explicit land use change model the spatial inputs are the input maps to calculate the suitability factors and the non-spatial input is the demand.

Systemic change means that a certain $\mathbf{f}$ and/or $\mathbf{p}$, which was at previous time steps able to give an accurate representation of the change in $\mathbf{y}_{t}$, has to be altered at a certain point in time to remain able to correctly simulate $\mathbf{y}_{t}$. This coincides with the special issue editors' description of systemic change as "entities no longer interrelating in a particular way" or "changes in the set of exogenous variables to which the system is sensitive".

The systemic change visible in $\mathbf{f}$ and/or $\mathbf{p}$ can be either direct or indirect. Direct means that an action, e.g. a policy change, directly affects $\mathbf{f}$ and/or $\mathbf{p}$. Indirect denotes that the action has an effect on the inputs $\mathbf{x}_{t}$, in such a way that the transition rules and parameters have to change as well (Filatova and Polhill, 2012). In other words, the behaviour of the inputs over time suddenly changes, beyond the function domain of $\mathbf{f}$, with the result that $\mathbf{f}$ becomes invalid.

\subsection{Land use change model}

The land use change model applied in our study is a branch of the PCRaster Land Use Change model (PLUC) (Verstegen et al., 2012), a spatially explicit LUC model. It is, like many other land use change models (Pontius and Neeti, 2010), grounded on the conceptual distinction between 1) the quantity of change per land use type, and 2) the spatial allocation of this change. The total quantity of land required per land use type, also called the demand $x_{d, n, t}$, is an input (present in $\mathbf{x}_{t}$ in Equation (1)), defined by historical data in historical runs, the identification phase, and by the scenario storyline in runs for future land use change, the projection phase. The change in demand, which can denote expansion as well as contraction, is allocated using the total suitability map $\mathbf{s}_{n, t}$, a weighted sum of the suitability factors for that land use type:

$$
\begin{aligned}
& \mathbf{s}_{n, t}=\sum_{k=1}^{K_{n}}\left(w_{n, k} \cdot \mathbf{u}_{n, k, t}\right), \text { for each } n \text { in each } t \\
& \text { with } \sum_{k=1}^{K_{n}}\left(w_{n, k}\right)=1 \\
& \text { and } \mathbf{u}_{n, k, t}=h\left(\mathbf{x}_{n, k, t}, \mathbf{p}_{n, k}\right)
\end{aligned}
$$

In Equation (2), $t$ is the time step in years, with $t=1,2, \ldots, T$; $n$ is the land use type, with $n=1,2, \ldots, N$; and $k$ is the suitability factor, with $k=1,2, \ldots, K_{n}$. Furthermore, $\mathbf{u}_{n, k, t} \in[0,1]$ is the suitability map for suitability factor $k$; and $w_{n, k} \in[0,1]$ is the weight of factor $k$, which denotes the importance of this specific proxy in the total suitability map $\mathbf{s}_{n . t}$. The suitability factors and their weights together establish the model structure of the LUC model, and are, just like the parameters $\mathbf{p}_{n, k}$, temporally and spatially constant as in most land use change models. The function $h\left(\right.$ ) uses the spatial attribute $\mathbf{x}_{n, k, t}$ and parameter(s) $\mathbf{p}_{k, t}$ to create the proxy for land use change, and normalizes it, i.e. linearly transforms it to a value between 0 and 1 , to obtain the suitability map for suitability factor $k, \mathbf{u}_{n, k, t}$. The transformation is linear, because the actual shape of the relation (linear, convex, concave) between $\mathbf{u}_{n, k, t}$ and $\mathbf{x}_{n, k, t}$ is determined by the parameters $\mathbf{p}_{n, k}$ within $\mathbf{u}_{n, k, t}$, discussed later. If required, areas where expansion is not allowed (no-go areas) can be masked out in the total suitability map, so that no change can occur in these cells.

Two types of suitability factors exist in PLUC: attraction or repulsion factors and feedback effects. Attraction/repulsion factors represent the attracting or repelling effect of a spatial attribute on a land use type. They are defined as:

$\mathbf{u}_{n, k, t}=\operatorname{norm}\left(c_{n, k} \cdot \mathbf{x}_{n, k, t}^{a_{n, k}}\right)$, for $k \in$ attraction/repulsion

In Equation (3), $\mathbf{x}_{n, k t}$ is the attribute of suitability factor $k$, e.g., potential yield. The parameter $a_{n, k}$ determines the shape of the suitability function. A value of 1 results in a linear function, meaning that suitability increases or decreases linearly with the increase in the value of the attribute. For $0<a_{k}<1$, the shape of $\mathbf{u}_{n, k, t}$ is concave, and for $a_{n, k}>1$, the shape is convex. Whether a certain attribute attracts (higher attribute values lead to a higher suitability) or repels (lower attribute values lead to a higher suitability) land use type $n$, is determined by the constant $c_{n, k}$, having a value of 1 in case of attraction and -1 in case of repulsion. The function norm() normalizes its contents, so that $\mathbf{u}_{n, k, t} \in[0,1]$.

Feedback effects characterize the positive effect of the presence of a land use type on the allocation of another land use type in a pre-defined neighbourhood. They represent temporal feedback in the system because the land use updated in the previous time step, $\boldsymbol{y}_{t-1}$, is used as an input, and thereby generate non-linear system behaviour. They are calculated as:

$\mathbf{u}_{n, k, t}=\operatorname{norm}\left(\mathbf{x}_{n, k, t-1}{ }^{2}+2 \cdot f_{n, k} \cdot l_{n, k, w}^{2} \cdot \mathbf{x}_{n, k, t-1}\right)$, for $k \in$ feedback

In Equation (4), $\mathbf{x}_{n, k, t-1}$ is the number of neighbours of the land use type of interest (usually land use type $n$ itself) in the neighbourhood window in time step $t-1$, derived from the system state in the previous time step $\boldsymbol{y}_{t-1}$. Parameter $l_{n, k, w}$ is the window length (in number of cells) of the window that determines whether or not a cell belongs to the neighbourhood. Furthermore, $f_{n, k}$ is the 'preferred' fraction of neighbours of the land use type of interest appearing in the total number of neighbours, that is $l_{n, k, w}^{2}$, within the window. Equation (4) creates a parabolic shape of $\mathbf{u}_{n, k, t}$ against $\mathbf{x}_{n, k, t-1}$. The rationale for this, is that e.g., financial and policy related principles can lead to a specific optimal number of neighbours. More as well as less neighbours than this optimum reduces the suitability $\mathbf{u}_{n, k, t}$. For example, for farmers it can be advantageous when some of their neighbours cultivate the same crop, for they can share machinery, but it can also be disadvantageous, as the land price increases due to this favourable situation under a growing demand.

Allocation of the demand $x_{d, n, t}$ occurs at each $t$ by sorting $\mathbf{s}_{n, t}$ and allocating cells to land use type $n$ until $x_{d, n, t}$ has been fulfilled. This mechanism (Equation (2) plus the allocation) is $\mathbf{f}$ in Equation (1). Systemic change concerning $\mathbf{f}$ can happen trough a required change in $w_{n, k}$. The land use map resulting from applying $\mathbf{f}$ is $\mathbf{y}_{t}$ in Equation (1). The inputs $\mathbf{x}_{t}$ in Equation (1) are $\mathbf{x}_{d, n, t}$ and $\mathbf{x}_{n, k, t}$ or $\mathbf{x}_{n, k, t-1}$, depending on $k$. The parameters $\mathbf{p}$ are $a_{n, k}, l_{n, k, w}$, and $f_{n, k}$.

We do not use a single, deterministic model run to simulate land use change, but an ensemble of runs, a Monte Carlo simulation (Verstegen et al., 2012; Aerts et al., 2003). For land use type $n$, in each cell, in each year, this ensemble represents the probability distribution of the occurrence of $n$. The ensemble is created by sampling from the prior probability distributions of the weights $\left(w_{n, k}\right)$ and parameters $\left(\mathbf{p}_{n, k}\right)$ of the suitability factors (equations (2)-(4)), and running the land use change model for each of the ensemble members $i$, with $i=1,2, \ldots, I$.

\subsection{Particle filter}

The ensemble of runs represents the range of possible model outcomes in each year given the uncertainty in model structure and parameters. The sequential importance resampling (SIR) particle filter (van Leeuwen, 2009) is a Bayesian estimation technique that uses observations to reduce the uncertainty in the ensemble, in our case to identify the optimal model structure and parameters. At a time step when observations are available, i.e. a filter moment, the particle filter solves Bayes' theorem for each ensemble member $i$, also called particle:

$$
p\left(\mathbf{z}_{t}^{i} \mid \mathbf{o}_{t}\right)=\frac{p\left(\mathbf{o}_{t} \mid \mathbf{z}_{t}^{i}\right) \cdot p\left(\mathbf{z}_{t}^{i}\right)}{p\left(\mathbf{o}_{t}\right)}=\frac{p\left(\mathbf{o}_{t} \mid \mathbf{z}_{t}^{i}\right) \cdot p\left(\mathbf{z}_{t}^{i}\right)}{\sum_{j=1}^{N} p\left(\mathbf{o}_{t} \mid \mathbf{z}_{t}^{j}\right) \cdot p\left(\mathbf{z}_{t}^{j}\right)}, \text { for each } i=1,2, \ldots, N
$$

In Equation (5), $p\left(\mathbf{z}_{t}^{i} \mid \mathbf{o}_{t}\right)$ is the posterior probability of the model state $\mathbf{z}_{t}^{i}$ of ensemble member $i$. The model state consists of the system states as well as the transition rules, inputs and parameters, i.e. $\mathbf{z}_{\mathrm{t}}=\left(\mathbf{y}_{\mathrm{t}}, \mathbf{f}, \mathbf{x}_{\mathbf{t}}, \mathbf{p}\right)$ (see Equation (1)). Thus, when $p\left(\mathbf{z}_{t}^{i} \mid \mathbf{o}_{t}\right)$ is updated, not only the system state $p\left(\mathbf{y}_{t}\right)$ is updated, but the probability distributions of the weights, $p\left(w_{n, k}\right)$, and of the parameters, $p\left(\mathbf{p}_{n, k}\right)$ are updated as well, because they are enclosed in the same ensemble member. Furthermore in Equation (5), $p\left(\mathbf{z}_{t}^{i}\right)$ is the prior probability of ensemble member $i$ and $p\left(\mathbf{o}_{t}\right)$ is the probability distribution of the observations, i.e. the measurement data and their uncertainty. If the observations are not of the state variable, but of a derived measure, the modelled system state $\mathbf{y}_{t}^{i}$ has to be converted to that measure before filtering. The prior probability of ensemble member $i$ is always equal to $1 /$ due to the sequential importance resampling (SIR) strategy (van Leeuwen, 2009). Namely, SIR samples a new set of $I$ ensemble members after each filter moment where the probability that an ensemble member is resampled equals the posterior probability of ensemble member $i$ in that filter moment. Finally, $p\left(\mathbf{o}_{t} \mid \mathbf{z}_{t}^{i}\right)$ is the probability of the observations given ensemble member $i$. Under the assumption that the observation error has a Gaussian distribution, the latter can be calculated as (van Leeuwen, 2009):

$p\left(\mathbf{o}_{t} \mid \mathbf{z}_{t}^{i}\right)=e^{-1 / 2\left[\mathbf{o}_{t}-\mathbf{H}\left(\mathbf{z}_{t}^{i}\right)\right]^{T} \mathbf{R}_{t}^{-1}\left[\mathbf{o}_{t}-\mathbf{H}\left(\mathbf{z}_{t}^{i}\right)\right]}$, for each $t$

In Equation (6), $\mathbf{H}$ is the measurement operator that transforms the model state to the observation, i.e. it selects the modelled system state $\mathbf{y}_{t}^{i}$ from $\mathbf{z}_{t}^{i}$ and, if necessary, converts it to the same support as the observations of the system state. $\mathbf{R}_{t}$ is the covariance matrix of the observation error and $T$ indicates matrix transposition. The diagonal elements of $\mathbf{R}_{t}$ represent variance of the observation error, $\boldsymbol{\sigma}_{o, t}^{2}$. The off-diagonal elements of $\mathbf{R}_{t}$ are relevant only when observation errors are correlated over space and/or time, otherwise they are zero.

We apply Equations (5) and (6) in two different ways (Fig. 1). The traditional way to use the particle filter is sequentially (see Fig. 1a) in order to, in the end, obtain $p\left(\mathbf{z}_{T} \mid \mathbf{o}_{T}\right)$, the posterior of the model state at the final time step $T$. We have used this method before to identify model structure (Verstegen et al., 2014). This approach 
a

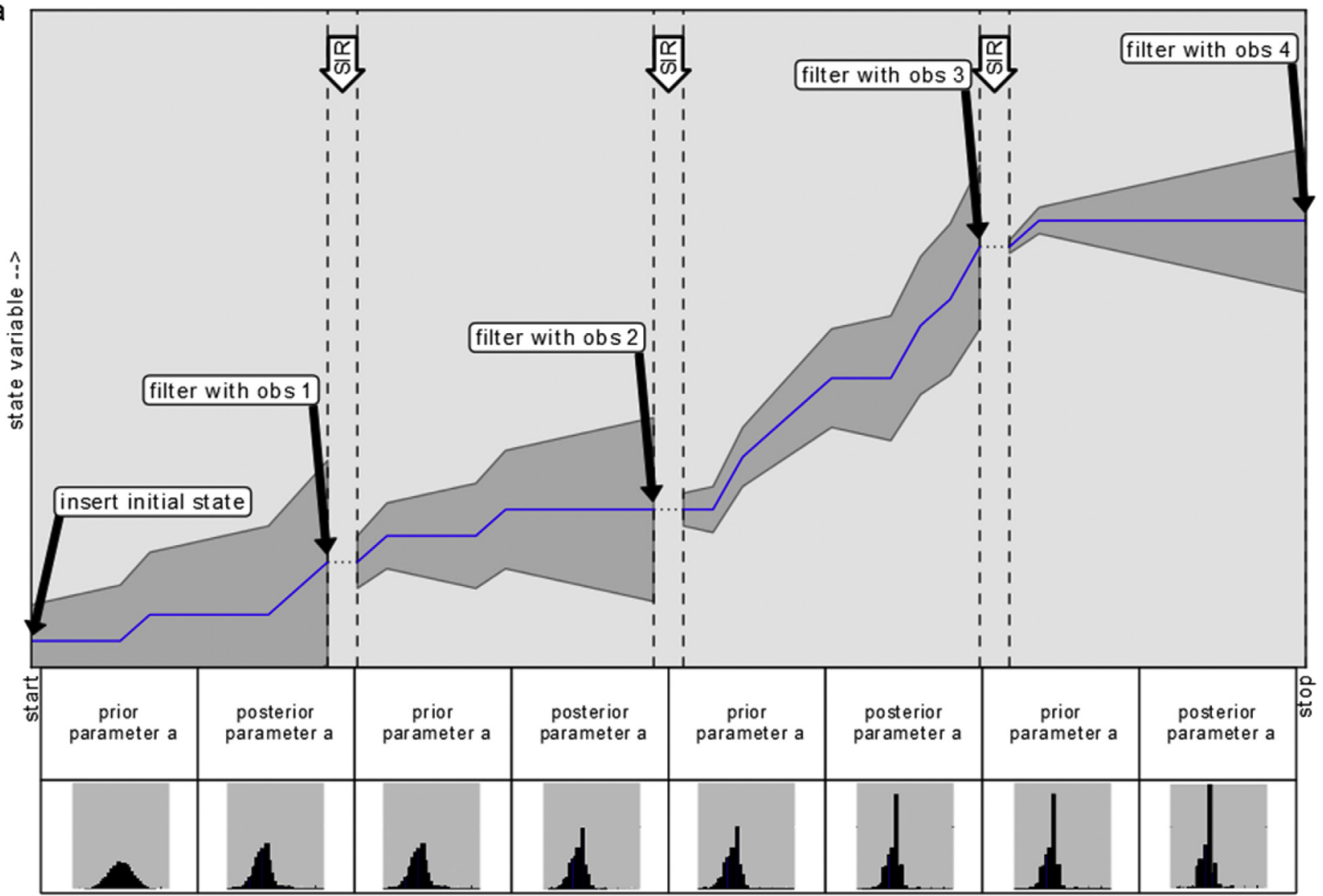

b

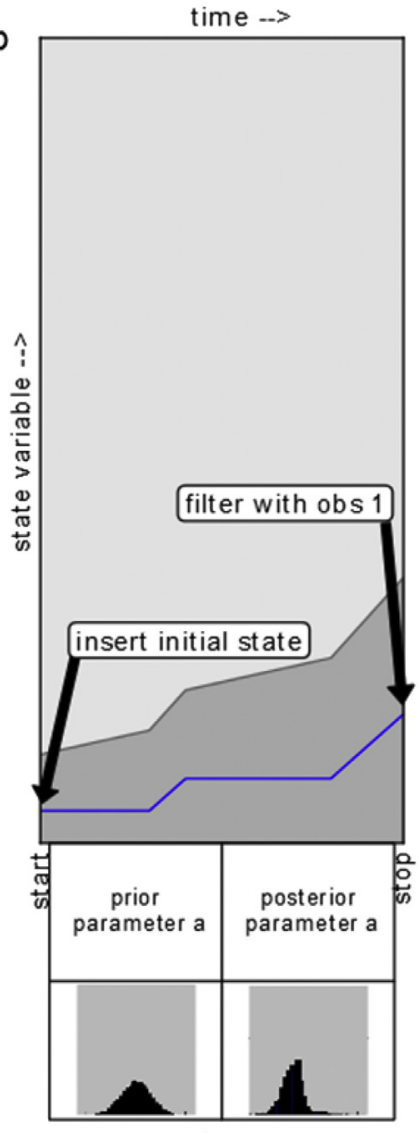

time -->
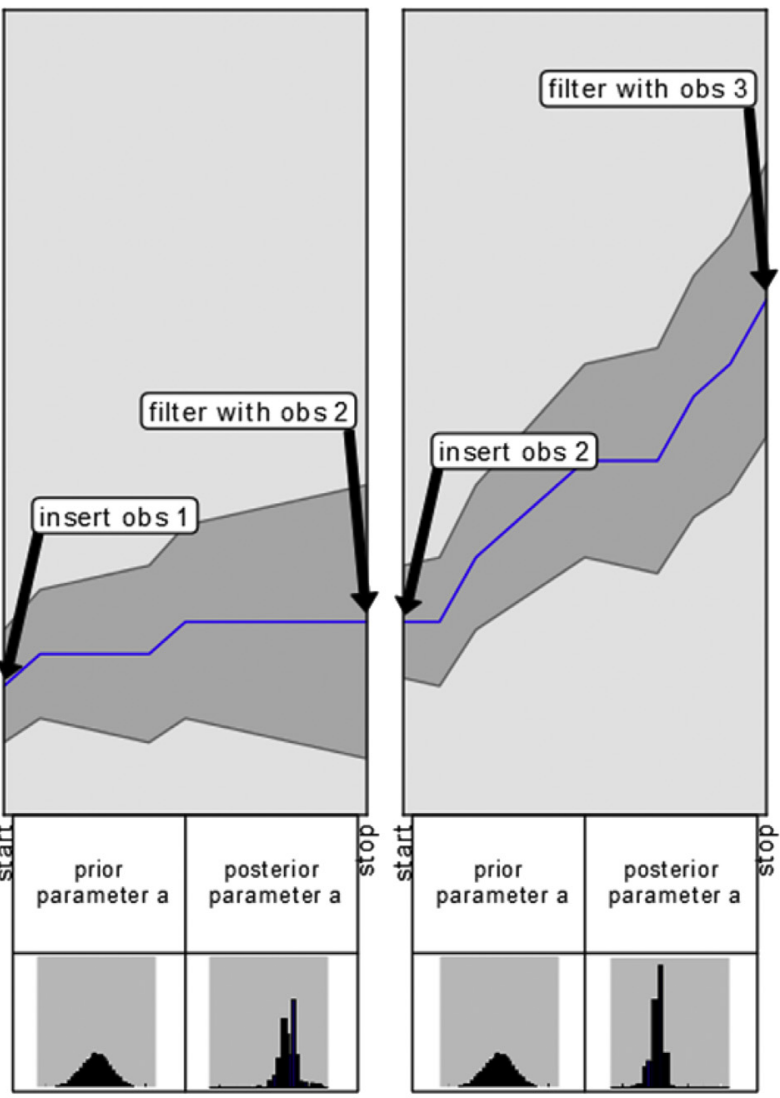

응

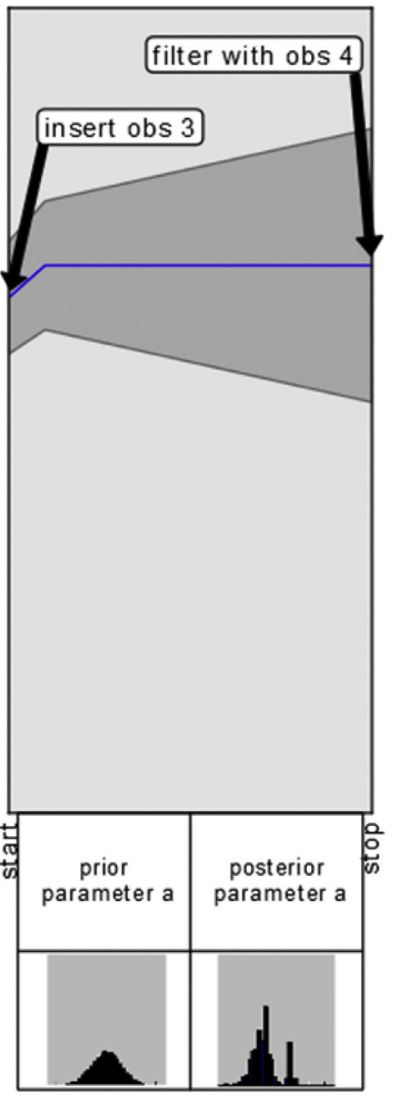

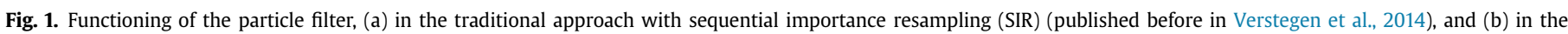

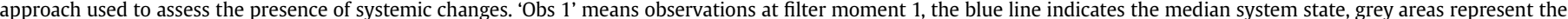

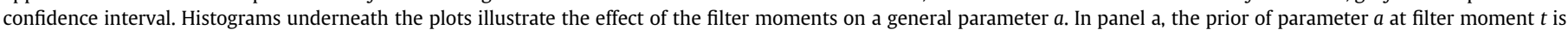

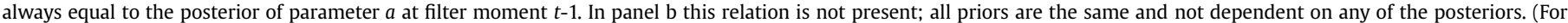
interpretation of the references to colour in this figure legend, the reader is referred to the web version of this article.) 
assumes a constant model structure and constant parameters: observations of the system state at a certain point in time are used as additional information about the best-fit model structure and parameters. So, although the number of ensemble members remains the same, due to the SIR, the variation in the ensemble members in terms of their uniqueness in parameter values will typically diminish over time. This means that the probability distributions of these parameters are gradually narrowed. This, however, also means that the approach does not work when parameters 'in reality' change over time, because there is no stationary parameter value the model state can converge towards. Therefore, this approach is suitable only under the assumption of model structure and parameter stationarity, i.e. no systemic changes.

Because in this paper we want to validate that assumption, we also apply Equations (5) and (6) in an atypical way (Fig. 1b). Observations of the system state at a certain point in time are used as distinctive information about the best-fit model structure and parameters at that point in time. Equations (5) and (6) are not applied sequentially, but separately at each filter moment. So, the model is initiated with the system state provided by $\mathbf{o}_{t-x}$ and is run up to the next filter moment, obtaining $p\left(\mathbf{z}_{t-x, t} \mid \mathbf{o}_{t}\right)$, where $x$ is the number of time steps between model start and filter moment. Next, the model is initiated with the system state provided by $\mathbf{o}_{t}$, with all parameters set to their initial prior probability distribution again, and the model is run up to the next filter moment. Using this approach, we find a distinctive $p\left(\mathbf{z}_{t-x, t} \mid \mathbf{o}_{t}\right)$ at every filter moment, not limited by previous observations, valid for period $t-\mathrm{x}$ to $t$ (one subplot in Fig. 1b). Hence, we can explore whether the optimal model structure and/or parameters vary significantly over time. If one of them does, the various observed system states cannot be simulated using a constant model structure and/or parameters, reflecting systemic change.

\subsection{Stationarity analysis}

Of course it can be viewed in a qualitative way whether the posterior probability distributions of the weights, $p\left(w_{n, k}\right)$, and of the parameters, $p\left(\mathbf{p}_{n, k}\right)$ vary notably over time, but it is more objective to use a quantitative test. Two general approaches exist to quantitatively test for stationarity: parametric and non-parametric tests (Grazzini, 2012). Parametric tests rely on the assumption that the distribution of the variable being sampled is known. Because this is often not the case for models of complex systems, like land use change models, a non-parametric test is more applicable (Lazante, 1996, Grazzini, 2012).

First, a non-parametric distribution comparison test is applied to check to what extent the distribution of a parameter at time $t$ differs from the average distribution over all other time steps $T^{*}$. In this test we first calculate a random variable $\mathbf{d}_{n, k, t}$ which represents the difference between the posterior distribution of a parameter at a particular time step and the mean of the parameter over all time steps. This is done in an approach similar to bootstrapping (Efron and Tibshirani, 2003), by subtracting a value randomly taken from the posterior distribution of a parameter at time step $t$ from a value randomly taken from the average distribution of this parameter over $T^{*}$. This is done $I$ times, i.e. as many times as we have Monte Carlo samples. If the posterior distribution of a parameter at time $t$ and the average distribution of this parameter over $T^{*}$ are the same, the resulting distribution $p\left(\mathbf{d}_{n, k, t}\right)$ is centred on zero. So, under the null hypothesis of stationarity $\left(H_{0}\right), p\left(\mathbf{d}_{n, k, t}\right)$ has an expected value of zero. To test this hypothesis, taking into account the full distribution of the parameter, we infer whether or not zero falls within the confidence interval of $p\left(\mathbf{d}_{n, k, t}\right)$ :

$H_{0}: Q_{\alpha / 2}\left(p\left(\mathbf{d}_{n, k, t}\right)\right)<0<Q_{1-(\alpha / 2)}\left(p\left(\mathbf{p}_{n, k, t}\right)\right)$, for each $t$

In Equation (7), $Q_{\alpha / 2}\left(p\left(\mathbf{d}_{n, k, t}\right)\right.$ is the $\alpha / 2$ percentile of $p\left(\mathbf{d}_{n, k, t}\right)$, e.g. the 2.5th percentile when verifying if $\alpha<0.05$. If the $H_{0}$ is rejected, there is systemic change in time $t$. The same is done for the weights.

The test above indicates the probability of systemic change in a certain parameter at a certain time step, but does not tell anything about the temporal correlation of potential deviations. To investigate this temporal correlation we use the non-parametric Wald-Wolfowitz test, also called Runs test (Wald and Wolfowitz, 1940). This test was successfully applied before to test for stationarity in a complex system model by Grazzini (2012). Given a time series and a function that aims to explain the trend in these time series, the values in the time series should be randomly distributed above and below the function, uncorrelated over time, if the function gives an adequate description of the time series. This is true regardless of the shape of the error distribution in the time series. Values above the function are labelled as + and values below the function are labelled as - . In the Runs test, a run is defined as a sequence of identical instances, i.e. either pluses or minuses. For example, the series,,,,,,,,+++-+--++ contains five runs, namely one run of three pluses, followed by a run of one minus, etc. In a time series containing a number of $N_{+-}$values, with random temporally uncorrelated errors, the expected, or mean, number of runs, $\mu_{r}$, is (Wald and Wolfowitz, 1940):

$\mu_{r}=\frac{2 N_{+} N_{-}}{N_{+-}}+1$

And the variance of $\mu_{r}$ is: $\sigma_{r}^{2}=\frac{2 N_{+} N_{-}\left(2 N_{+} N_{-}-N_{+-}\right)}{N_{+}^{2}\left(N_{+-}-1\right)}$

In Equations ( 8 ) and (9), $N_{+}$is the number of plus instances, $N_{-}$is the number of minus instances. Using this probability distribution of the number of runs, the Runs test checks whether the null hypothesis of randomness can be rejected or not. In other words, it checks whether the distribution of values in the time series above and below the function can be considered random, uncorrelated over time, given a certain level of significance $\alpha$. If it is not, the function is not an appropriate representation of the time series. When one uses a constant value for this function, one can test whether this constancy, of e.g. a parameter, is a correct representation of this parameter in the studied system. If it is not, there is a systemic change in our definition (Section 2.1).

\section{Case study}

\subsection{Background}

A case study on sugar cane cropland expansion in São Paulo state is set up to examine the presence of systemic changes in a land use system. Expansion of the sugar cane area is related to an increasing demand for both sugar and ethanol. Brazilian ethanol production from sugar cane is seen as one of the most efficient biofuel technologies currently available, and it is profitable without subsidies, so in the future the expansion is expected to continue (Sparovek et al., 2009; Walter et al., 2011; Cerqueira Leite et al., 2009). Sugar cane cultivation in Brazil is concentrated in the South-Central region (Rudorff et al., 2010). This region, which includes São Paulo state, has been annually mapped since 2003 in the Canasat project (Rudorff et al., 2010) with an overall thematic accuracy of $98 \%$ (Adami et al., 2012a), providing a reliable time series of observational data for the particle filter.

Within the period between 2003 and 2012, a number of societal changes in Brazil might have caused systemic change in the sugar cane expansion. The review provided here is a reflection of societal changes that were deemed of importance by the authors after consultation of literature and experts, and should therefore not be considered exhaustive. We focus on developments that potentially change the spatial allocation of sugar cane, not the quantity of change (demand) as in PLUC the demand is exogenous (Section 2.2). We provide hypotheses of how they might change the model structure or parameters when this is not immediately clear.

Some policy changes in the last decade may have had, and are in fact established to have, an effect on the land use system. According to Sparovek et al. (2010) "Land-use modelers exploring the Brazilian case generally pay little attention to the influence of legal aspects, i.e., how Brazilian regulations influence agriculture, including the size and spatial distribution of the expansion potential". Therefore we discuss these aspects in detail, and explore whether they can be traced as systemic changes in our case study. Firstly, sugar cane straw is currently often burned before harvesting the sugar cane to improve the safety of the 'cane cutters' and to increase the yield. The Brazilian government tries to eliminate preharvest burning because it has negative effects on human health and on the environment due to the emission of pollutant gases (Aguiar et al., 2011). Replacing manual harvesting by mechanical harvesting can eliminate pre-harvest burning, because mechanical harvesting does not require burning. However, the harvest machines cannot operate on sloping ground; $12 \%$ is considered the maximum slope for mechanical harvesting (Macedo, 2007). Therefore, schemes are established, specifying the maximum area on which pre-harvest burning can be practiced as a proportion of the total sugar cane area, per slope category per year (Fig. 2). With the most recent of the three schemes, the Green Ethanol protocol, compliance is not obligatory, but can be advantageous for the producers because the protocol resembles importer's preferences and offers a first step towards certification. By 2008, 145 out of the 

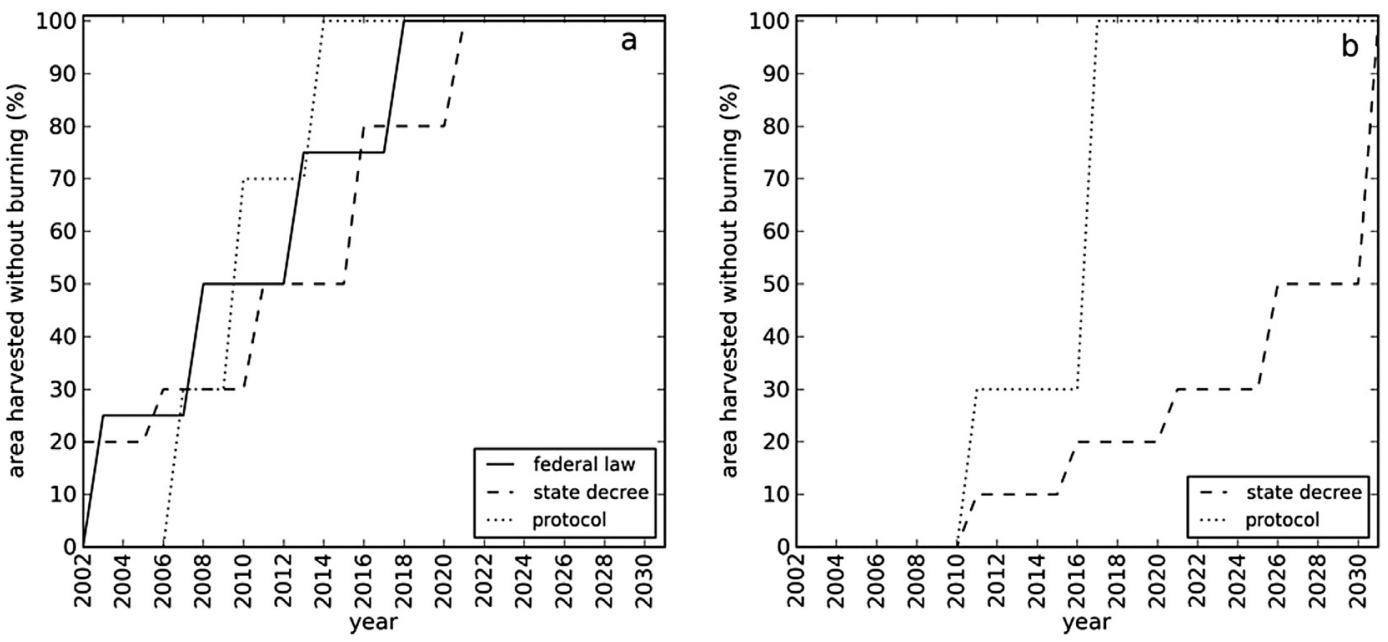

Fig. 2. Schemes specifying the required area without pre-harvest burning as a proportion of the total sugar cane area (a) for slopes $\leq 12 \%$ and (b) for slopes $>12 \%$.

177 ethanol plants in São Paulo complied to the protocol, representing $89 \%$ of total cane crushing (Lucon and Goldemberg, 2010). However, a study by Aguiar et al. (2011) for the years 2009 and 2010 shows that in some areas the harvesting system was shifted in the wrong direction in these years, i.e. from green harvest to harvest with burning.

The second important policy change is the initiation of sugarcane agro-environmental zoning (AEZ) in São Paulo in 2008 (Lucon and Goldemberg, 2010). Using eight physical indicators (climate, surface water, slope, ground water, biodiversity protection areas, biodiversity connectivity, and integral protection units) a map with four categories is created: suitable, moderately restricted, highly restricted, and unsuitable for sugar cane cultivation (Padua Junior et al., 2012). The initiative of the state zoning has led to the launch of the federal Sugarcane Agro-ecological Zoning (ZAE Cana) in 2009 (Lucon and Goldemberg, 2010). It uses similar physical indicators, and in addition aims to protect the Amazon and Pantanal biomes and Upper Paraguay River Basin. The initiation of these zonings might increase the importance of physical suitability factors in the model structure.

A third policy change that might have had an effect on the spatial allocation of sugar cane is the adaptation of the Forest Act, or Forest Code, in 2012. The Forest Act, established in 1965, is the main legal framework in Brazil for natural vegetation (not only forest) conservation. Among other things, it specified the fraction of the farmland that should be set aside for biodiversity conservation, meaning that natural vegetation should be kept in place. This fraction was $35 \%$ inside the Legal Amazon, and $20 \%$ outside. A low compliance in the past and several amendments of the Forest Code between 1965 and 2012 that allowed farmers to sometimes preserve lower fractions of farmland, had put a large part of the Brazilian farmers in an illegitimate situation (Sparovek et al., 2012). As this illegality was a national and international (certification) problem and total compliance with the prescribed fractions through vegetation restoration would be too costly, a revision of the Forest Act was accepted in 2012. The exact rules in the new Forest Act remain vague up to this point in time. It is expected that it maintains the preservation requirements for future expansion, but legalizes the farmers' situation for those who deforested illegally before 2008 (Costa and Gray, 2011). The story goes that, as the process of the revision started already in 2009, farmers anticipated on the new Forest Code since then by accelerated illegal forest cutting, hoping that amnesty would be granted, but, as far as we know, this is not scientifically proven. In the model the new Forest
Code might affect the neighbourhood suitability factor or the parameters herein that determine the 'preferred' fraction of neighbours, $f_{n, k}$ (Equation (4)), as a percentage of the land cannot be used for cultivation.

Economically, many developments have taken place affecting the sugar cane sector, and it goes beyond the scope of this paper to discuss them in detail. Obviously, the crisis in 2008 may have affected the sugar cane demand (model input) but also the spatial distribution. The crisis led to a discontinuation of investments, forcing farmers to produce at older, less productive sites (Gómez, 2013), and to postpone modernization of agricultural machinery (Aguiar et al., 2011). The latter might cause farmers to care less about the slope of the field, since they cannot afford machinery to harvest mechanically anyway.

Finally, a shift not in the human but in the environmental system that could affect the allocation of sugar cane is that Brazil has experienced some bad harvests between 2009 and 2011. Aguiar et al. (2010) report that from season 2006/2007 to 2008/2009 the area of sugar cane left unharvested has gone up from 3.0 to 4.1 to $11.6 \%$. They believe that this was related to unfavourable harvest weather conditions as well as delays in constructing planned mills, with the result that the mills were not operational in time. In $2009 / 2010$ the unharvested area rose to $18.1 \%$, thereafter decreasing to $6.9 \%$ and $1.0 \%$, reaching $4.1 \%$ in the season $2012 / 2013$ (Aguiar et al., 2011, Aguiar, Personal communication, July 17th 2014).

\subsection{Model setup}

The land use change model described in Section 2.2, is applied to the São Paulo case study as follows (Table 1$)$. Sugar cane $(n=1)$ is the only 'active' land use type, i.e. a land use type responding to a demand, thus $N=1$. The suitability map for sugar cane expansion $\mathbf{s}_{1, t}$ (Equation (2)) is calculated using four suitability factors $\left(K_{1}=4\right)$, derived from discussions with experts and literature review (Rudorff et al., 2010; Adami et al., 2012a; Walter et al., 2011; Aguiar et al., 2011; Sparovek et al., 2012, 2007; Lapola et al., 2010; de Souza Soler and Verburg, 2010, Macedo and Seabra, 2008) (Table 1). A similar model setup has been calibrated before with the particle filter, resulting in a minimum reduction factor of 3 in the root mean square error of three spatial metrics compared to the reference model (Verstegen et al., 2014). Sugar cane in the neighbourhood $(k=1)$ is expected to be important because larger plantations require less investment costs per hectare as equipment and 
Table 1

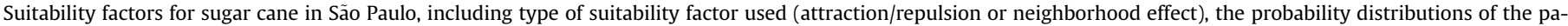
rameters $\left(\mathbf{p}_{1, k}\right)$, and the data sources. The probability distributions of the stochastic variables, e.g., $Z_{w_{1, k}}$, represent prior distributions; during filtering they change.

\begin{tabular}{|c|c|c|c|c|}
\hline$k$ & 1 & 2 & 3 & 4 \\
\hline Suitability factor & Sugar cane in neighbourhood & Distance to sugar cane mills & Potential yield & Slope \\
\hline Process represented & Economies of scale & $\begin{array}{l}\text { Transportation costs to } \\
\text { processing units }\end{array}$ & Profits & Mechanization potential \\
\hline Weights $\left(w_{1, k}\right)$ (equation $\left.(2)\right)$ & $\begin{array}{l}w_{1,1}=\frac{Z_{w_{1,1}}}{\sum_{k=1}^{4}\left(Z_{w_{1, k}}\right)} \\
\text { with } Z_{w_{1, k}} \sim U(0,1)\end{array}$ & $w_{1,2}=\frac{Z_{w_{1,2}}}{\sum_{k=1}^{4}\left(Z_{w_{1, k}}\right)}$ & $w_{1,3}=\frac{Z_{w_{1,3}}}{\sum_{k=1}^{4}\left(Z_{w_{1, k}}\right)}$, & $w_{1,4}=\frac{Z_{w_{1,4}}}{\sum_{k=1}^{4}\left(Z_{w_{1, k}}\right)}$ \\
\hline Type of suitability factor & Neighbourhood effect (equation (4)) & Attraction/repulsion (equation (3)) & $\begin{array}{l}\text { Attraction/repulsion } \\
\text { (equation (3)) }\end{array}$ & $\begin{array}{l}\text { Attraction/repulsion } \\
\text { (equation (3)) }\end{array}$ \\
\hline $\begin{array}{l}\text { Parameters }\left(\mathbf{p}_{1, k, t}\right) \\
\quad \text { (equations (3) and (4)) }\end{array}$ & $\begin{array}{l}l_{1,1, w}=e^{Z_{l}}, \text { with } Z_{l_{w}} \sim N(9.6,0.7) \\
f_{1,1}=Z_{f_{1,1}}, \text { with } Z_{f_{1,1}} \sim U(0,1)\end{array}$ & $\begin{array}{l}a_{1,2}=e^{Z_{a_{1,2}}, \text { with }} Z_{a_{1,2}} \sim N(0,1.8) \\
c_{1,2}=-1\end{array}$ & $\begin{array}{l}a_{1,3}=e^{Z_{a_{1,3}}} \\
\text { with } Z_{a_{1,3}} \sim N(0,1.8) \\
c_{1,3}=1\end{array}$ & $\begin{array}{l}a_{1,4}=e^{Z_{a_{1,4}}} \\
\text { with } Z_{a_{1,4}} \sim N(0,1.8) \\
c_{1,4}=-1\end{array}$ \\
\hline Original map attribute for $\mathbf{x}_{1, k, t}$ & Sugar cane & Location of mills & Potential yield & Digital elevation model \\
\hline Map source & Rudorff et al., 2010 & Picoli, 2013 & Tóth et al., 2012 & Farr et al., 2007 \\
\hline
\end{tabular}

infrastructure can be shared. The distance from the field to the sugar cane mill $(k=2)$ determines the transportation costs of sugar cane to the processing unit. The distance to the mill is expected to be more eminent than the distance from the mill to the distribution centre, because the end product (ethanol or sugar) has a higher energy density than the sugar cane and thus lower transport costs per energy unit. Potential yield $(k=3)$, an indicator linking agroclimate conditions to crop requirements, is important for the potential revenues per hectare. Slope $(k=4)$ defines the potential for sugar cane harvest mechanization (see Section 3.1). Table 1 gives more details about the parameterization of the processes described above.

The total area of São Paulo state is about $250,000 \mathrm{~km}^{2}$ and a resolution of $5 \mathrm{~km}$ is used. We purposefully model at a resolution larger than the average farm size in Brazil. The land tenure system in Brazil is complex and includes farms managed by the mill, farms held by the mill and leased to a farmer, farms held by the farmer with a contract obligation to deliver to a certain mill for a fixed price, farms held by a farmer having no such contract, and other constructions (see e.g., Sparovek et al., 2007). Spatial data on this with a complete coverage is not available so modelling at farm level would have limited value as the inputs of such a model are highly uncertain. Apart from this, a much finer resolution would increase model run time which hampers the application of the Monte Carlo based particle filter. By aggregating to a cell size of several farms we hope to average out the effects related to the land tenure situation of the individual farmer and focus more on general sugar cane expansion trends, resulting in a model with a relatively short run time.

The model is run in two phases: an identification phase, in which we identify the relative importance of the suitability factors and their parameterization (Table 1) and try to recognize systemic changes; and a projection phase, in which we use this information to propagate the land use change (further explained in Section 3.4). In total $T$ is 20 time steps, with $t=1$ representing the year 2003. The initial land use map (a Boolean map: 1 = sugar cane, 0 = no sugar cane) is the 2003 Canasat map (Rudorff et al., 2010), which has a resolution of $30 \mathrm{~m}$, resampled to the model resolution $(5000 \mathrm{~m})$. The resampling is done in such a way that the total sugar cane area in the resampled map matches the total sugar cane area in the original map, i.e. the demanded area for sugar cane is harmonized because this is an important model input. Note that the class 'no sugar cane' is passive: it has no demand and can only change through conversion by the active land use type 'sugar cane'.

So, the input variable 'demand' is in the identification phase simply the total area of sugar cane found in the Canasat maps (Fig. 3). In the projection phase two data sources are used to construct the demand. The first is the Brazilian Land Use Model (BLUM) (ICONE, 2012; Nassar et al., 2008), an economic partial equilibrium model, and the second is the Brazilian agricultural economics institute, IEA (Torquato, 2006). As we have equal trust in both sources, the demand in PLUC from 2013 to 2022 is the mean of the two time series created from these sources (Fig. 3).

\subsection{Particle filter setup}

The data assimilation framework in the PCRaster Python framework (Karssenberg et al., 2010) is used for the particle filtering. The data used to create the observational data are nine annual maps of sugar cane occurrence (Rudorff et al., 2010), from 2004 to 2012 (the data of 2003 is used as the initial system state). We, together with others (e.g., Parker et al., 2008), believe that the purpose of land use change models is not, and should not be, to simulate precisely the land use of each single cell in each year. For this reason, we do not use the sugar cane map directly as $\mathbf{o}_{t}$ (equation (5)), but calculate the fraction of sugar cane in $25 \times 25 \mathrm{~km}$ blocks and take that as $\mathbf{o}_{t}$. In total the study area consists of 473 of such blocks, making the length of the array $\mathbf{o}_{t} 473$. Obviously, we also convert the model output to that measure (fraction of sugar cane in $25 \times 25 \mathrm{~km}$ blocks) before filtering.

The observational data has two error sources: 1 ) errors in the classification of the remote sensing image and 2) errors from the upscaling to a larger cell size. We assume that there is no spatial or temporal correlation in the errors of the observational data, so only the diagonal elements of $\mathbf{R}_{t}$ need to be defined, i.e. the variances of the observation error, $\boldsymbol{\sigma}_{o, t}^{2}$.

A study by Adami et al. (2012b) shows that the user's accuracy (the probability that a cell classified as a certain class is actually that class (Lillesand et al., 2003)) of the Canasat data is 0.97 for the sugar cane class and 0.98 for the no-sugar cane class. To obtain the standard deviation, $\sigma_{o, t, u}$, for the $25 \times 25 \mathrm{~km}$ blocks belonging to these user's accuracies, we simulate for every potential fill of a block (0-100\% sugar cane) $1 \cdot 10^{5}$ events where sugar cane cells have a probability of 0.03 to become no-sugar cane, and no-sugar cane cells have a probability of 0.02 to become sugar cane. The results indicate that $\sigma_{o, t, u}$ is linearly related to the fraction of sugar cane per block, as:

$$
\sigma_{o, t, u}^{2}=\left(2.8 \cdot 10^{-2}+1 \cdot 10^{-2} \cdot \mathbf{o}_{t}\right)^{2}, \text { for each } t
$$

The upscaling error arises from the fact that in the modelled land use in a cell is either sugar cane or no sugar cane (Boolean), while in the data the fraction of sugar cane per cell is given, leading 


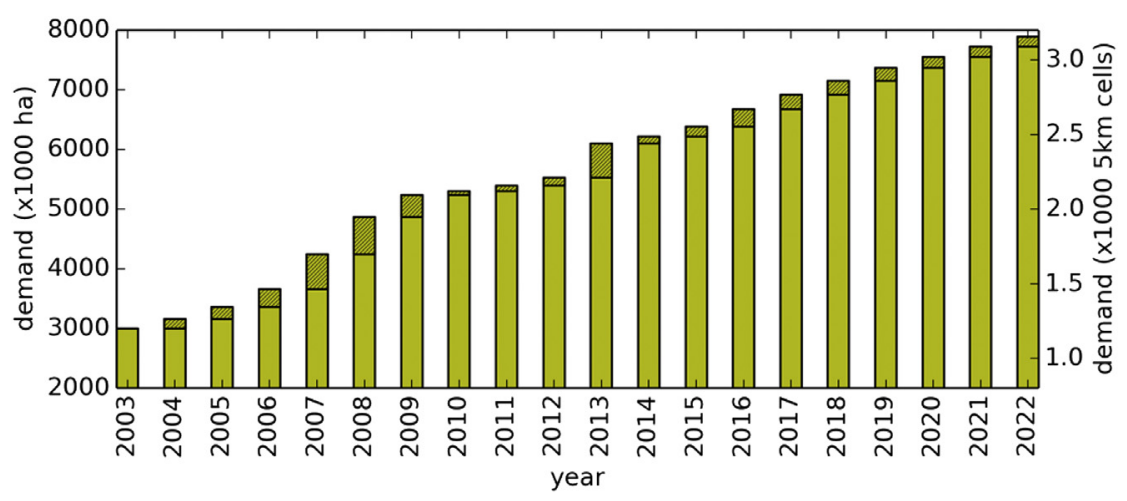

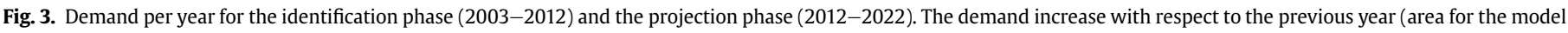
to allocate) is hatched to enhance visibility of variation over time in this demand increase.

to a difference between model output and observations. This error has a maximum of $100 \%$ (a cell has in reality a sugar cane fraction of 0.5 , but the model output is 0 or 1 ) and a minimum of $0 \%$. The distribution of this error is difficult to estimate, because it depends on the observed values. For this reason we assume normality of this error (required to fulfil the conditions of equation (6)) and apply its maximum possible size of $0.5 \cdot \mathbf{o}_{t}$ to all observations.

Combining these two error sources, the total variance of the observations is:

$\boldsymbol{\sigma}_{o, t}^{2}=\left(2.8 \cdot 10^{-2}+5.1 \cdot 10^{-1} \cdot \mathbf{o}_{t}\right)^{2}$, for each $t$

We are aware of the fact that we have made a strong assumption about the shape and magnitude of the variance, but we want to stress that the stationarity test used to detect systemic change (see Sections 2.4 and 3.4) employs only the mean of the posterior and not the full distribution. This diminishes the effect of this assumption on the conclusions about systemic change.

\subsection{Stationarity analysis setup}

For the distribution comparison test (Equation (7)), instead of assuming an $\alpha$ value and reporting whether or not $H_{0}$ is rejected, we calculate the $\alpha$ belonging to the tipping point between rejection and no rejection, which is more transparent. This $\alpha$ value gives the probability that $H_{0}$ is unjustly rejected, i.e. the probability that we assume systemic change in this parameter at $t$ while in fact there is stationarity. Hence, low $\alpha$ values indicate a high probability of systemic change. The Runs test is applied as follows. For the posterior distributions of the weights $\left(w_{n, k}\right)$ and parameters $\left(\mathbf{p}_{n, k}\right)$ of the suitability factors (Equations $(2)-(4)$ ), obtained separately for each observation time frame $\left(p\left(\mathbf{z}_{t-x, t} \mid \mathbf{o}_{t}\right)\right.$, Fig. 1b), the overall mean is obtained. This overall mean is the function aiming to explain the trend in time series of posteriors. Next, the mean per posterior distribution, i.e. per observation time, is obtained, and assigned a +

Table 2

Scenario setup regarding observational data (synthetic or Canasat (Rudorff et al., 2010)), filter method, and projection method.

\begin{tabular}{llll}
\hline Scenario & $\begin{array}{l}\text { Observational } \\
\text { data }\end{array}$ & Filter (2004-2012) & Projection (2013-2022) \\
\hline 1 & Synthetic & Method Fig. 1b & - \\
2 & Canasat & Method Fig. 1b & $\begin{array}{l}\text { Using a trend or random } \\
\text { posterior from all } p\left(\mathbf{z}_{t-x, t} \mid \mathbf{o}_{t}\right) \\
\text { depending on the results }\end{array}$ \\
3 & Canasat & Method Fig. 1a & Using posteriors from 2012 \\
\hline
\end{tabular}

if it is above the overall mean and a - if it is below. On this sequence the Runs test is applied, and the p-value is reported, indicating the probability that the pattern found in the deviations from the mean is random. If the null hypothesis of randomness is rejected, $\mathbf{f}$ and/or p in Equation (1) cannot be considered stationary, so a systemic change is present. Note that the Runs test checks only if an average value in the time series is above or below the mean and not how much it is above or below. Therefore, the detection of systemic change should be based on the combined results of visual inspection of the means, the distribution comparison test and the Runs test.

\subsection{Scenarios}

Three scenarios are run (Table 2). By the word 'scenario' we do not mean a scenario storyline, i.e. a potential development pathway of the land use system, but a model setup designed to investigate a specific property of the used method or studied system. All scenarios are run using an ensemble of 5000 members.

In the first scenario, the ability of the particle filter to detect the correct weights $\left(w_{n, k}\right)$ and parameters $\left(\mathbf{p}_{n, k, t}\right)$ is tested using a synthetic dataset. The synthetic dataset is created by running the model deterministically with the demand equal to the demand in the Canasat data (Rudorff et al., 2010) (Fig. 3) and the settings specified in Table 3. These settings do not change over time. Next, the model is run stochastically and the particle filter is applied separately for each year (the method shown in Fig. 1b) from 2004 to 2012 using the synthetic data as observations $\mathbf{o}_{t}$. If the method is working correctly, the distributions of the weights $\left(w_{n, k}\right)$ and parameters $\left(\mathbf{p}_{n, k}\right)$ should converge to the values in Table 3 in all years, i.e. the particle filter should trace back settings that were applied to generate the synthetic dataset.

In the second scenario, we run a new ensemble, applying the particle filter separately for each year, but now with the Canasat observational data of sugar cane distribution. Potentially, significantly different posterior distributions of the weights and

Table 3

Model settings for the synthetic dataset: the weights $\left(w_{1, \mathrm{k}}\right)$ and parameters $\left(\mathbf{p}_{1, \mathrm{k}}\right)$, $l_{1, k, w}$, neighborhood window length, $f_{1, k}$, neighborhood fill, and $a_{1, k}$, suitability function shape parameter, for $k=1,2,3,4$

\begin{tabular}{|c|c|c|c|c|}
\hline$k$ & $\begin{array}{l}\text { 1, sugar cane in } \\
\text { neighbourhood }\end{array}$ & $\begin{array}{l}2, \text { distance to } \\
\text { sugar cane mills }\end{array}$ & $\begin{array}{l}3 \text {, potential } \\
\text { yield }\end{array}$ & 4 , slope \\
\hline Weights $\left(w_{1, k}\right)$ & $w_{1,1}=0.25$ & $w_{1,2}=0.25$ & $w_{1,3}=0.25$ & $w_{1,4}=0.25$ \\
\hline $\begin{array}{c}\text { Parameters } \\
\left(\mathbf{p}_{1, k}\right)\end{array}$ & $\begin{array}{l}l_{1,1, w}=15,000 \mathrm{~m} \\
f_{1,1}=0.5\end{array}$ & $a_{1,2}=1$ & $a_{1,3}=1$ & $a_{1,4}=1$ \\
\hline
\end{tabular}




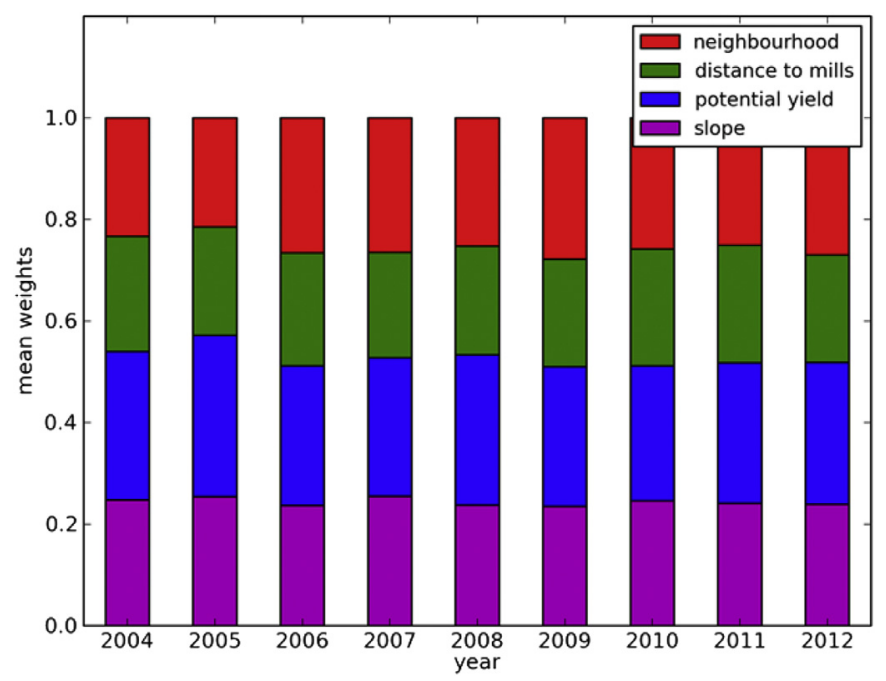

Fig. 4. Mean of the posterior distributions of the weights of the suitability factors, $w_{1, k}$, obtained with synthetic observational data (scenario 1 ).

parameters are obtained in each year. If any kind of trend or connection to the societal changes can be detected in distributions, this trend is prolonged in the projection phase (2013-2022). If no trend is apparent, and no connection to societal changes can be found, we assume that for each time step in the projection phase any of the systems found in the identification phase can be valid. So in each projection year (2013-2022) a posterior model state $p\left(\mathbf{z}_{t-x, t} \mid \mathbf{o}_{t}\right)$, containing probability distributions of the weights, $p\left(w_{n, k}\right)$, and of the parameters, $p\left(\mathbf{p}_{n, k}\right)$, is drawn randomly from all posteriors model states of the identification years (2004-2012). The projection phase of scenario 2 is run five times to cover the uncertainty arising from the diverse sequences of posteriors that are drawn.

In the third scenario, the traditional particle filter method with Sequential Importance Resampling (Fig. 1a) is applied, again with the Canasat data. During the projection phase, the posterior distribution of the final year is used, $p\left(\mathbf{z}_{T} \mid \mathbf{o}_{T}\right)$, because this posterior contains information from the whole identification phase.

\section{Results}

\subsection{Identification with synthetic data}

For scenario 1, the means of the posterior distributions of the weights, $w_{1, k}$, converge to values around 0.25 (Fig. 4), as expected since these were the values used to generate the synthetic dataset (Table 3 ). The weight of distance to sugar cane mills, $w_{1,2}$, is on average 0.03 too low, 0.22 , and the weight of potential yield, $w_{1,3}$, is on average 0.03 too high, 0.28 . The other two are on average exactly 0.25 . No significant trends are visible over time, which is confirmed by the distribution comparison test (average $\alpha$ values all very high, $>0.85$ ) and the Runs test (Table 4). The complete posterior distributions of the weights and the posterior distributions of the parameters are given in Appendix A. The distributions of parameters $a_{1,2}, a_{1,3}$, and $a_{1,4}$ in all years, and the distributions of the parameters $l_{1,1, w}$ and $f_{1,1}$ in all years but 2006 to 2009 remain broad, indicating that the parameters are difficult to identify. The Runs test concludes non-stationarity for four out of the five parameters, but the distribution comparison test does not for any $\alpha$ below 0.2 .

Table 4

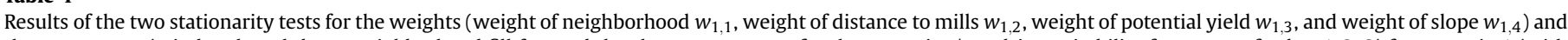

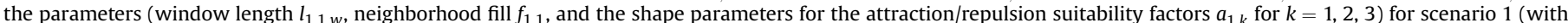

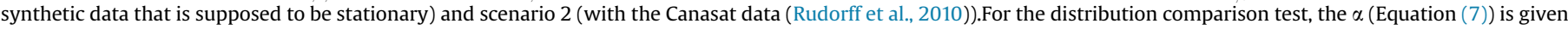

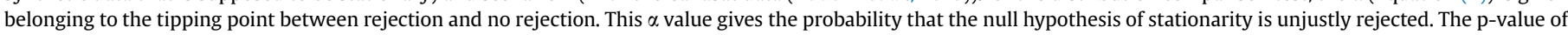

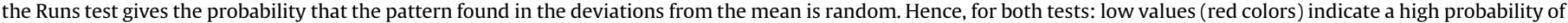
systemic change and high values (green colors) indicate a high probability of stationarity.

\begin{tabular}{|c|c|c|c|c|c|c|c|c|c|c|c|c|}
\hline & year & 2004 & 2005 & 2006 & 2007 & 2008 & 2009 & 2010 & 2011 & 2012 & & \\
\hline variable & scenario & \multicolumn{9}{|c|}{ probability ( $\alpha$ in Equation 7) of unjustly rejecting stationarity } & $\begin{array}{c}\text { average } \\
\alpha\end{array}$ & $\begin{array}{c}\text { p-value } \\
\text { Runs } \\
\text { test }\end{array}$ \\
\hline \multirow{2}{*}{$w_{1,1}$} & 1 & 0.82 & 0.65 & 0.93 & 0.93 & 0.91 & 0.79 & 0.98 & 0.96 & 0.9 & 0.87 & 0.66 \\
\hline & 2 & 0.54 & 0.48 & 0.68 & 0.07 & 0.11 & 0.64 & 0.97 & 0.85 & 0.83 & 0.57 & 0.05 \\
\hline \multirow{2}{*}{$w_{1,2}$} & 1 & 0.99 & 0.9 & 0.98 & 0.92 & 0.98 & 0.93 & 0.94 & 0.95 & 0.89 & 0.94 & 0.66 \\
\hline & 2 & 0.96 & 0.97 & 0.89 & 0.67 & 0.6 & 0.62 & 0.69 & 0.79 & 0.99 & 0.8 & 0.15 \\
\hline \multirow{2}{*}{$w_{1,3}$} & 1 & 0.97 & 0.82 & 0.91 & 0.84 & 0.91 & 0.87 & 0.87 & 0.95 & 0.97 & 0.9 & 0.21 \\
\hline & 2 & 0.86 & 0.74 & 0.49 & 0.16 & 0.25 & 0.31 & 0.85 & 0.95 & 1 & 0.62 & 0.04 \\
\hline \multirow{2}{*}{$w_{1,4}$} & 1 & 0.99 & 0.94 & 0.97 & 0.88 & 0.98 & 0.96 & 1 & 0.98 & 0.99 & 0.97 & 0.66 \\
\hline & 2 & 0.86 & 0.95 & 0.86 & 0.41 & 0.41 & 0.45 & 0.97 & 0.96 & 0.93 & 0.76 & 0.05 \\
\hline \multirow{2}{*}{$l_{1,1, w}$} & 1 & 1 & 0.92 & 0.82 & 0.17 & 0.28 & 0.38 & 0.75 & 0.93 & 0.93 & 0.69 & 0.04 \\
\hline & 2 & 1 & 0.86 & 0.31 & 0.02 & 0.01 & 0.61 & 0.79 & 0.97 & 0.92 & 0.61 & 0.04 \\
\hline \multirow{2}{*}{$f_{1,1}$} & 1 & 0.78 & 0.99 & 0.76 & 0.32 & 0.62 & 0.33 & 0.71 & 0.8 & 0.87 & 0.69 & 0.04 \\
\hline & 2 & 0.44 & 0.16 & 0.87 & 0.88 & 0.34 & 0.21 & 0.22 & 0.53 & 0.59 & 0.47 & 0.01 \\
\hline \multirow{2}{*}{$a_{1,2}$} & 1 & 0.58 & 0.7 & 0.57 & 0.47 & 0.77 & 0.43 & 0.56 & 0.57 & 0.7 & 0.59 & 0.04 \\
\hline & 2 & 0.05 & 0.08 & 0.04 & 0.94 & 0.3 & 0.83 & 0.36 & 0.23 & 0.24 & 0.34 & 0.59 \\
\hline \multirow{2}{*}{$a_{1,3}$} & 1 & 0.86 & 0.92 & 0.52 & 0.23 & 0.43 & 0.26 & 0.71 & 0.76 & 0.62 & 0.59 & 0.04 \\
\hline & 2 & 0.54 & 0.57 & 0.33 & 0.46 & 0.53 & 0.19 & 0.43 & 0.43 & 0.37 & 0.43 & 0.01 \\
\hline \multirow{2}{*}{$a_{1,4}$} & 1 & 0.63 & 0.57 & 0.54 & 0.44 & 0.51 & 0.6 & 0.57 & 0.6 & 0.61 & 0.56 & 0.15 \\
\hline & 2 & 0.41 & 0.54 & 0.49 & 0.7 & 0.85 & 0.88 & 0.58 & 0.64 & 0.65 & 0.64 & 0.66 \\
\hline
\end{tabular}




\subsection{Identification with Canasat data}

For scenario 2, the means of the posterior distributions of the weights, $w_{1, k}$, (Fig. 5) imply that all four selected suitability factors are relevant in the land use system, because none of them receives a zero weight. On average, distance to the mills appears to be the most important suitability factor in determining where sugar cane expands. Next most important are sugar cane in the neighbourhood and slope, switching over time between second and third most important. Least important, but still relevant with an average weight of 0.1 , is potential yield.

The mean weight of distance to sugar cane mills appears to be stationary (Fig. 5). This is confirmed by the Runs test, using, for example, a 5\% significance level (Table 4). The distribution comparison test confirms this; it has the highest average $\alpha$ value and also the most constant $\alpha$ value over time, indicating the highest probability of stationarity. The mean weights of the other factors clearly change over time (Fig. 5). In the period 2006 to 2008, the mean weight of sugar cane in the neighbourhood is $54 \%$ higher than in the other years, and the weight of potential yield is $24 \%$ lower. Slope has a $67 \%$ lower weight that persists one year longer. This non-stationarity, indicating systemic change, is confirmed for all three factors by the distribution comparison test, with low $\alpha$ values in especially 2007 and 2008, and the Runs test, and is strongest for potential yield (Table 4).

In the parameters, $\mathbf{p}_{n, k, t}$, the systemic change is visible as well (Fig. 7), although the uncertainty in the parameter values is mostly high. From 2006 to 2008 the mean window size of the neighbourhood, $l_{1,1, w}$, is about $50 \%$ smaller than in the other years. The $\alpha$ values are very low, 0.02 and 0.01 in 2007 and 2008 (Table 4), indicating systemic change. The neighbourhood fill, $f_{1,1}$, on the contrary, is more stable over time, around a value of 0.1 , except in the first two years, when it is about 0.2 . For the parameters $a_{1, k}$, for $k=1$, 2,3 , the stability over time is more difficult to observe because of the large uncertainty. This can also be concluded from the distribution comparison test, which gives few low $\alpha$ values, except for $a_{1,2}$ in 2004-2006. For all weights (Fig. 6) and the parameters $l_{1,1, w}$ and $f_{1,1}$ (Fig. 7) the posteriors in the period 2006 to 2009 are narrower than in the other years.

The start of the systemic change, 2006, is a year with no identified societal changes (Fig. 5). The 'recovery' period of the system,

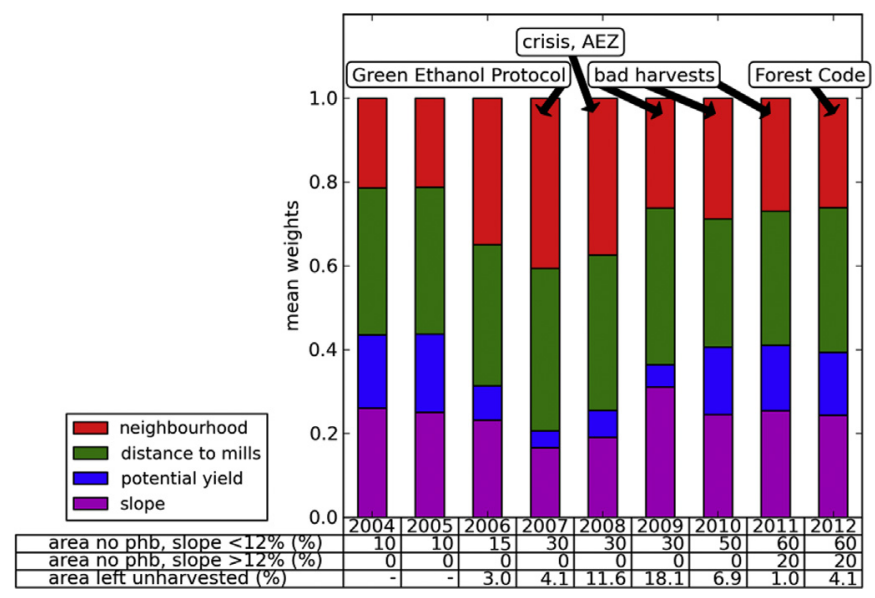

Fig. 5. Mean of the posterior distributions of the weights of the suitability factors, $w_{1, k}$, obtained with Canasat observational data (Rudorff et al., 2010) (scenario 2). Occurrences of societal changes, discussed in Section 3.1, are indicated above the bar graph. Minimum percentage of sugar cane area that should be harvested without pre-harvest burning (phb) per year (average of the state and Green Ethanol Protocol requirements, Fig. 2) is indicated below the bar graph, together with the percentage of sugar cane area left unharvested.
2009 to 2010, coincides with the years of bad harvests, and a percentage of sugar cane fields left unharvested more than twice as high as in previous years (Aguiar et al., 2010). In 2010, the average area on which pre-harvest burning is forbidden increases from 30 to $50 \%$ for slopes below $12 \%$. The potential connection between the societal changes and the observed systemic change is considered in the discussion section (5.2).

Filtering with Canasat data (Rudorff et al., 2010) using the traditional particle filter method (scenario 3) (Fig. 8) yields the same order of importance of the suitability factors (distance to mills, neighbourhood and slope, potential yield) as found in scenario 2 (Fig. 5). However, the posterior distributions of the weights in scenario 3 are narrower than the posterior distributions (per year) in scenario 2 (Fig. 6). And, obviously, variation in the weights over time cannot be detected in scenario 3, as only one posterior distribution is obtained per weight (Fig. 8).

\subsection{Projection}

Because no trend is detected in the posteriors of the weights and parameters in the identification phase that could be extrapolated, in each projection year (2013-2022) a posterior is drawn randomly from the posteriors of the identification years (2004-2012). The projection phase of scenario 2 is run five times to cover the uncertainty arising from the diverse potential sequences of drawn posteriors. Scenario 3 is run once, because it always yields the same result. The projection of the fraction of sugar cane per $25 \times 25 \mathrm{~km}$ block shows little difference between scenario 2 and 3 in the median expansion trend of the selected blocks (Fig. 9); the lines in the upper and lower panel have similar courses and end up at similar values in 2022. However, the 95\% confidence interval in this trend in scenario 2 is on average twice as large as in scenario 3.

\section{Discussion}

\subsection{Identification with synthetic data}

From the fact that in scenario 1 the weights of the suitability factors converge to approximately the correct mean value of 0.25 (maximum error is 0.03 ), we conclude that the particle filter is successful in inferring the weights. For the variation in this mean over time, the Runs test gives high p-values (0.21-0.66), meaning that there is no reason to reject the null hypothesis that this variation is caused by randomness: the weights are almost certainly stationary, as expected.

The relatively weak convergence of the parameter values in most years indicates that the parameters perform equally well (or badly) over their complete prior distribution. So we conclude that the sugar cane distribution data does not contain sufficient information for inferring the parameters using the particle filter at this resolution. This could be related to the spatial averaging of the model results and observations to the $25 \times 25 \mathrm{~km}$ blocks in the particle filter. The parameters should be stationary over time, but the Runs test denotes non-stationarity. However, this result is unreliable because of the large uncertainty in the parameters. The distribution comparison test, that does take into account the full posterior distributions, does not indicate systemic change, supporting the conclusion that the low identifiability of the parameter makes the Runs test unsuitable. In future research other types of data may be used for inferring the parameters, or the parameters may be fixed and only the weights calibrated. So, in this case study the test for systemic change in model structure and/or parameterization should be focused on the model structure. 

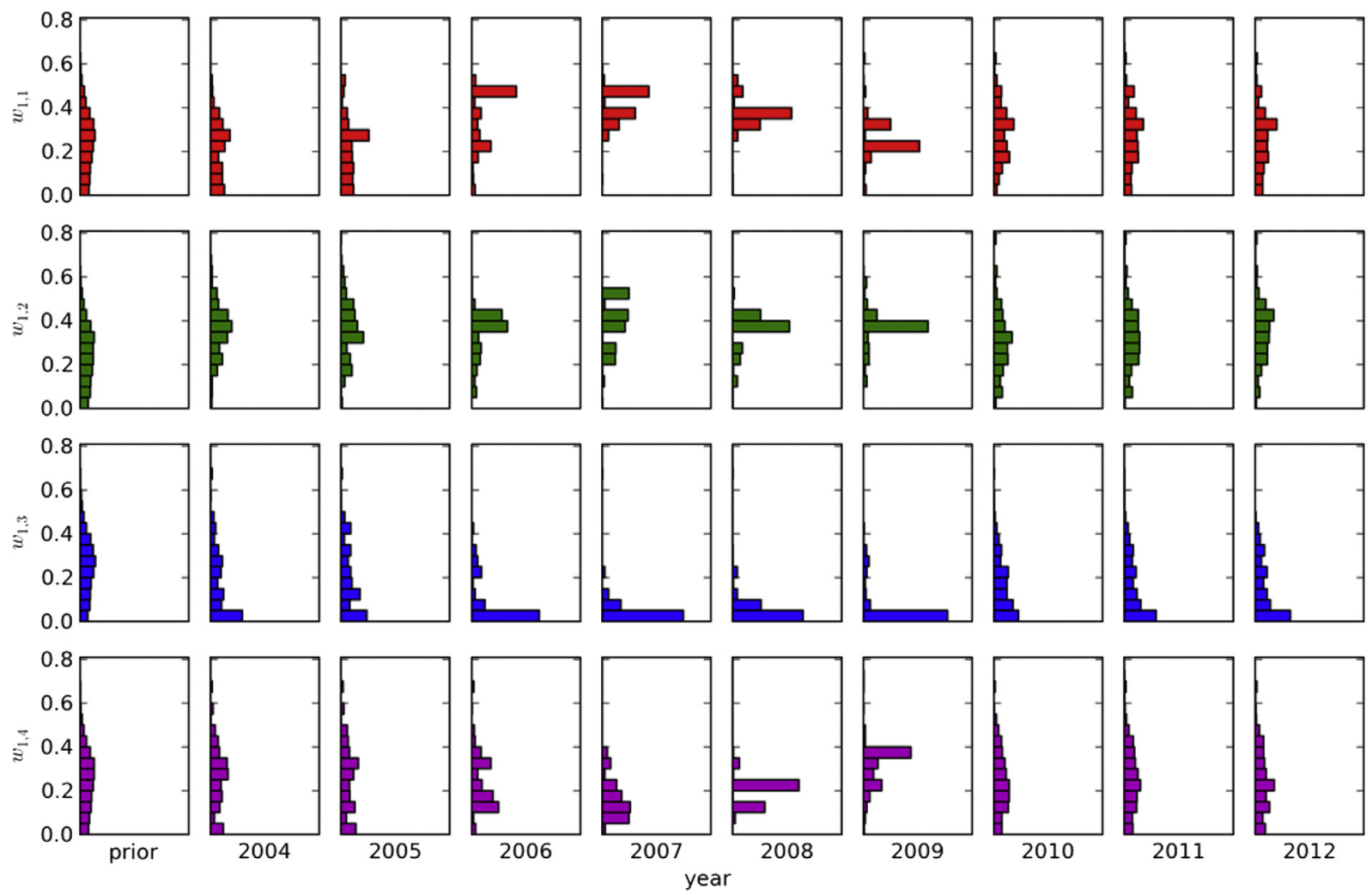

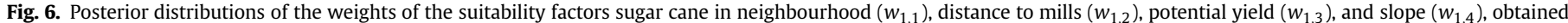
with Canasat observational data (Rudorff et al., 2010) (scenario 2).
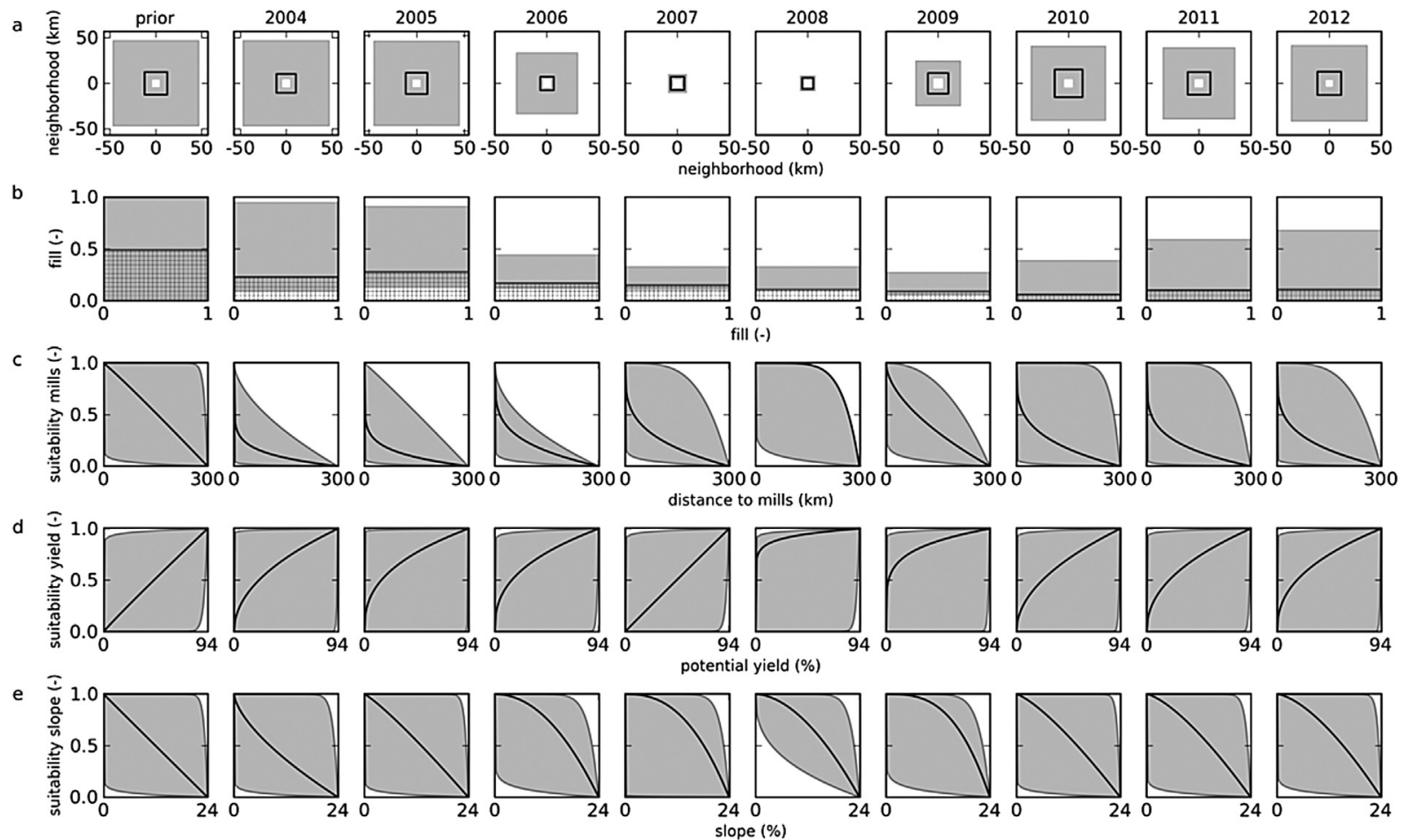

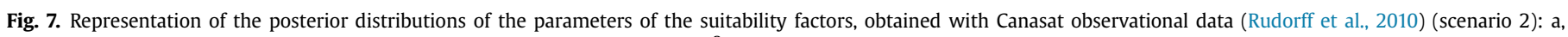

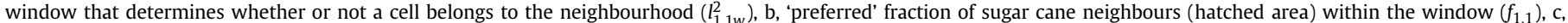

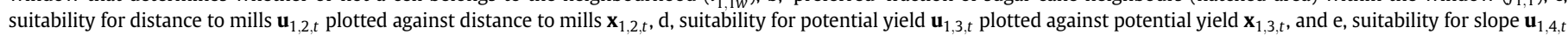
plotted against slope $\mathbf{x}_{1,4, t}$. Black lines represent the median of the parameter value, grey areas are $95 \%$ confidence intervals. 

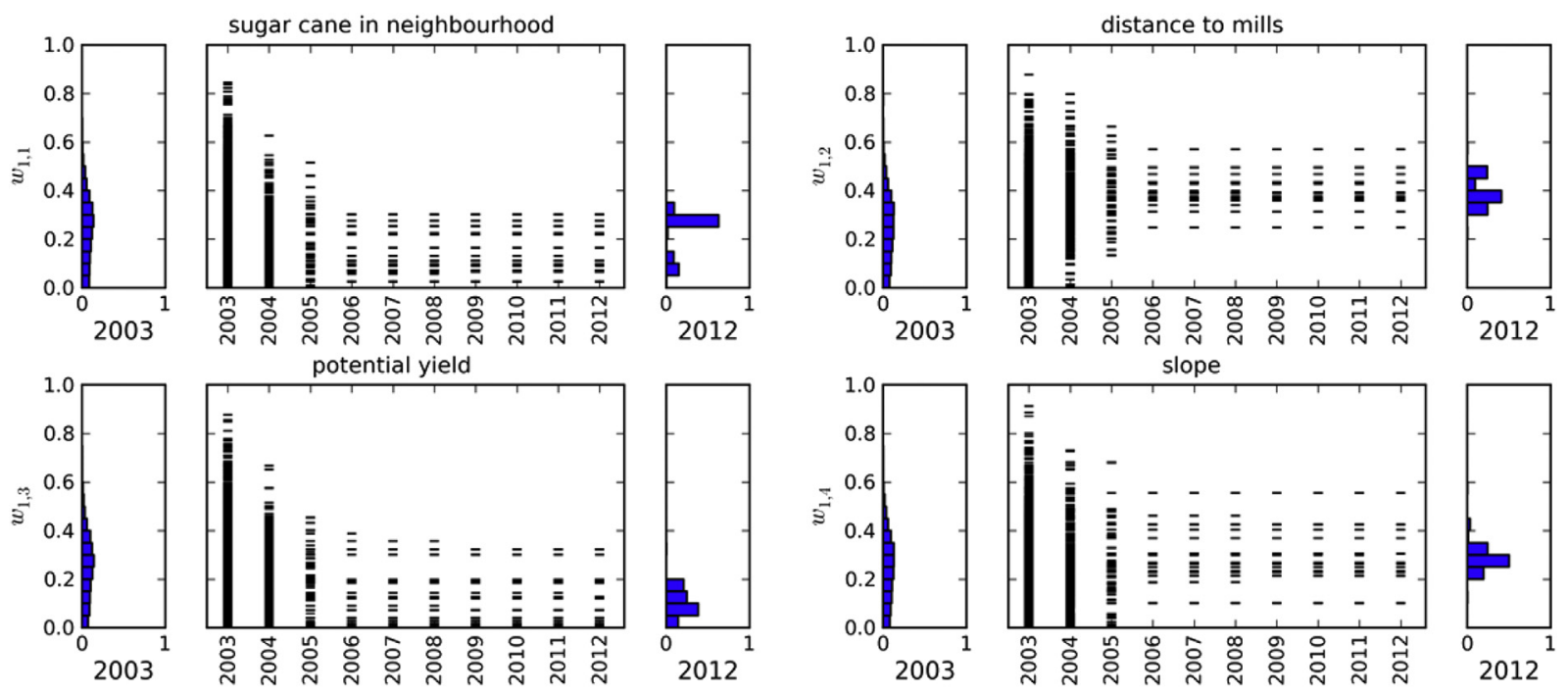

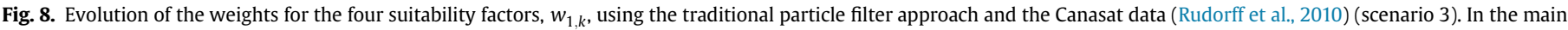
panels the black horizontal lines represent the ensemble members. The smaller panels on the left and right give the full prior (2003) and posterior (2012) distributions.

\subsection{Identification with Canasat data}

In scenario 2, non-stationarity is observed for three out of the four weights of the suitability factors (Table 4), indicating a period of systemic change. It concerns the weights of sugar cane in the neighbourhood, potential yield, and slope, in the period 2006 to 2008/2009. The weight of the neighbourhood suitability factor becomes higher, while the weights of slope and potential yield become lower (Fig. 5). This implies that in determining where to create a new sugar cane field, existing fields in the neighbourhood become more important, and the slope of the land and potential yield, and therefore the mechanization potential and expected revenues, become less important. In addition, it appears that the neighbourhood window that is used to look for existing sugar cane fields in the vicinity becomes smaller (Fig. 7), i.e. expansion of sugar cane occurs closer to existing fields. However, in the previous section it was concluded that we should be careful in interpreting the results for the parameters, because the scenario with synthetic data implied that they cannot be fully trusted.

The systemic change is gradual and reaches its maximum in 2007 (Table 4). Looking at the societal changes in the studied period that we considered of possible influence (Section 3.1), there are two policy changes: the adoption of one of the schemes for the phasing out of pre-harvest burning (Aguiar et al., 2011; Gallardo and Bond, 2011) and the implementation of the agro-environmental zoning (Lucon and Goldemberg, 2010). Yet, these two policies are expected to increase the importance of the suitability factor slope, while in the identified systemic change period the weight decreases. The economic crisis in 2008 is also an unlikely candidate for the cause of the change, because the systemic change clearly starts already in 2006, when the crisis was not yet foreseen. In conclusion, given our shortlist of potential causes for systemic changes, no cause can be found for the onset of systemic change. Nevertheless, the low weight of the suitability factor potential yield in 2008 and 2009 a

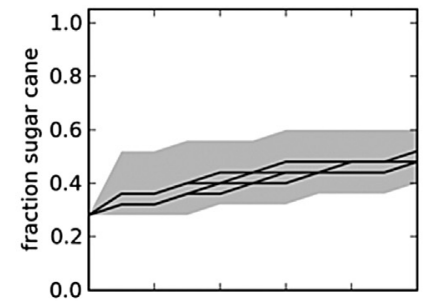

b

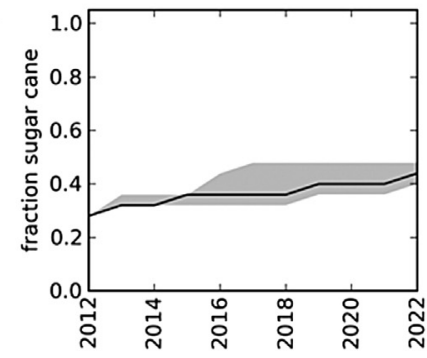

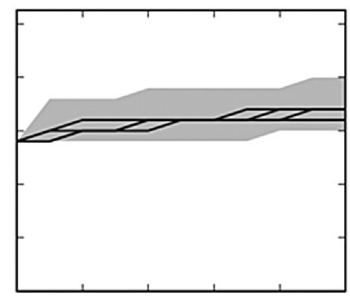

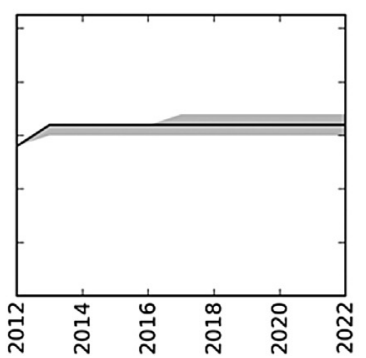

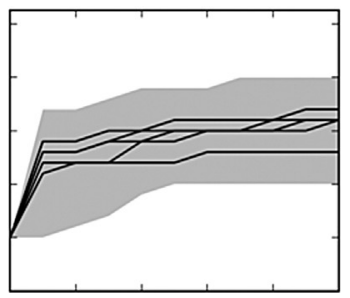

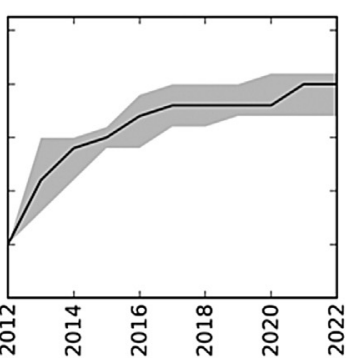

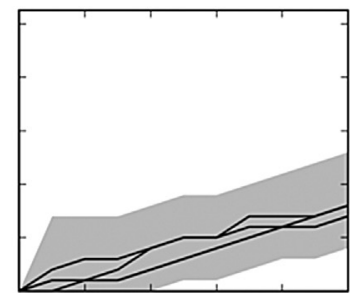

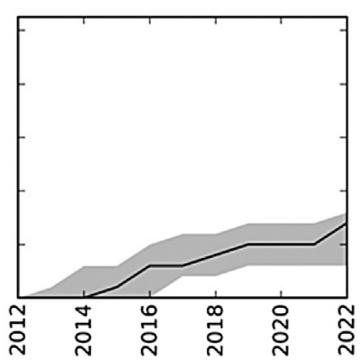

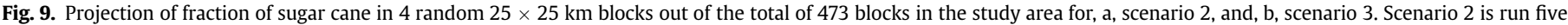

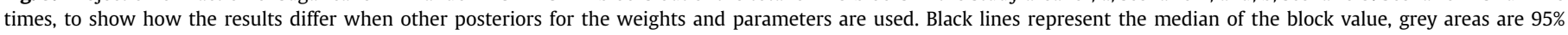
confidence intervals (for scenario 2 calculated over all values of the five runs together). 
confirms the conclusion of journalists that the crisis forced, by a discontinuation of investments, sugar cane production at older, less productive sites (Gómez, 2013). A potential explanation of the recovery of the system in 2009, to its functioning before 2006, are the bad harvests from 2009 to 2011 and the consequential larger share of fields left unharvested. The changed system in which the importance of potential yield was low, was possibly not maintainable anymore, because bad weather usually has a relatively large influence on already low yielding soils.

Remarkable is the relation between the demand increase (Fig. 3) and the systemic change. The years 2006-2009 have a demand increase above average, the exact same period as the systemic change, with maxima in 2007 and 2008. This implies an indirect systemic change: an action has an effect on the input 'demand', in such a way that the transition rules and/or parameters have to change as well (Filatova and Polhill, 2012). A possible reasoning behind the connection between fast demand increase and an increase in the weight of the neighbourhood suitability factor is that a sudden upsurge in demand increase is difficult to predict for farmers. New farmers, searching new locations, may not have time to respond to the upsurge, but existing farmers, already having the machines and infrastructure, can expand their existing fields in response to the upsurge. This results in the fact that expansion is more guided by existing sugar cane cultivation than by optimal conditions (slope and potential yield) for new fields. The existing fields are already close to mills, so this suitability factor remains of equal importance. However, other explanations might be possible as well.

The fact that most of the societal changes cannot be traced in our results does not mean that they have no effect at all on the sugar cane expansion system in São Paulo; it only means that they have no effect on the sugar cane expansion system in São Paulo given our model setup, observational data and resolution. Optimal model structure, and consequently stationarity, is thus different at different resolutions, as also noted by Pontius and Spencer (2005). For example, one would expect that the adoption of a new scheme for the phasing out of pre-harvest burning (Fig. 2) results in an increase of the weight of the suitability factor slope, but this was not observed in this study. At a different resolution, considering a longer time period (there might be a time lag), considering different suitability factors, or using a different implementation of the currently used suitability factors the effects can possibly be observed. In this case we studied the systemic changes using block averages of sugar cane coverage as model outputs and observations. If systemic changes are studied based on spatial patterns, like number of patches, or landscape shape index (Pijanowski et al., 2002) the conclusion can be different. However, the advantage of using areal averages of land use is that this measure cannot be derived only from land use maps, but also from agricultural statistics databases. Where time series of land use maps of sufficient length are not always available, time series of agricultural statistics usually are, showing the large applicability of the shown approach. But, to be able to draw a conclusion on the impact of societal changes, or more specific the effectiveness of policies, the methodology should be applied with various model setups, with different spatial patterns in the observational data, at various resolutions. This was, however, not the aim of our study. Also, the single land use type is an oversimplification. Applying the particle filter on a land use model with multiple land use types, using an agricultural statistics database as observations, is the next stage of our research.

The lower standard deviations in the period 2006 to 2009 compared to the other years can be explained by the information content of the observations. In the given period the demand increase is relatively large, as mentioned before. This implies allocation of a relatively high number of sugar cane cells in those years. With this greater amount of change, the particle filter can better detect the optimal relative importance and parameterization of the suitability factors, so the convergence of the probability distributions will be stronger. As a reference: when there is no demand increase or decrease at all, the particle filter can never identify the optimal model structure, because the observations contain no information (no change). It is important to note here that the information content of the observations is not the reason for the detected systemic change, because in scenario 1 (synthetic data) the same demand time series was applied, and the model structure was stationary.

\subsection{Projection}

The 95\% confidence interval for the projected fraction of sugar cane per block is twice as large for scenario 2 compared to scenario 3 (Fig. 9), indicating that the use of a different posterior in each year results in a higher uncertainty regarding the dynamics of fraction of sugar cane in a block. Still, caution should be taken in generalizing this quantitatively. If it is true that the systemic change in the identification period is related to changes in demand increase, the model structure used in the projection period should depend on projected demand. Nonetheless, if one assumes that different system structures that have existed in the past are valid, in any order, in the future, uncertainty in the projection of land use change becomes considerably higher. Although it was not analysed in this study, it is even possible that the uncertainty arising from the potential systemic changes in the future is so large that variation in the results of different storylines completely disappears. This is something that should be kept in mind when conducting land use change projections, especially over long time intervals.

Instead of representing changes in the model structure by a random approach, as is done here, it would be preferable to extend the model by including processes representing the systemic change itself. This would enable better forecasting of future changes as variation in the model structure becomes a function of the state or inputs of the modelled system itself. For example, one can connect the land use change model to a transportation model to account for changes in accessibility (e.g., Aljoufie et al., 2013), or to an erosion model to represent changing landscape features (e.g., Claessens et al., 2009). However, in our study the causes for the systemic change were not clearly identified, so dealing with systemic change by including the societal changes causing them was not achievable. We foresee that this will also be unachievable in many other land use change modelling studies, as often the knowledge of the system and the data availability are insufficient to fully understand and model the systemic changes.

\section{Conclusion}

Our first aim in this paper was to develop a general methodology, applicable to any type of model, to test for systemic change. In the methodology observations of the real system are assimilated into the model, using a particle filter (van Leeuwen, 2009). The particle filter was used to update the prior knowledge about the model structure, in the case of our land use change model the selection and relative importance of suitability factors, and parameters during model runtime at years for which observations of real land use were available (2004-2012) (see also Verstegen et al., 2014). Using the particle filter separately for each point in time for which a land use map was available, we have obtained optimal model structures for these different points in time. 
One limitation of our methodology is the strong assumption about the uncertainty in the observations. Also, the land use change model that was used to test the methodology was relatively simple, with only one active land use type. Another problem is that the two statistical tests used to provide evidence for the systemic changes, did not always give high significance levels. Therefore, we hope that this study serves as an eye opener to the potential presence of systemic change, in land use systems as well as in other modelling domains, and as a first step towards a sound methodology to test for systemic changes.

Given these limitations, we still believe that some conclusions can be drawn about systemic change in our case study of sugar cane expansion in the São Paulo state in Brazil. Here, the assumption of a constant model structure was not an adequate representation of the land use system given a time series of observations of past land use. A visual inspection and an analysis of the quantity of variation in the distinctive posterior distributions of the suitability factor weights and parameters, as well as the outcome of two statistical tests on these distributions have provided a strong indication of non-stationarity in the model structure and parameters, i.e. systemic change.

The systemic change appeared to be indirect: something has an effect on the input demand for sugar cane, in such a way that the transition rules and parameters have to change as well (Filatova and Polhill, 2012). But, although an inventory was made of societal changes in the study area during the studied period, none of these could be related to the onset of the observed systemic change in the land use system in 2006. The recovery of the system, in 2008 or 2009 , might be related to a few years of bad harvests, forcing farmers to focus more on potential yield when selecting a new field.

Because no clear reason was detected for the model structure and parameter changes in the identification period, we assumed that a future land use system could be any of the land use systems found in the identification period. Applying this resulted in an increase of the $95 \%$ confidence interval of the projected fraction of sugar cane by a factor of two compared to the assumption that the future land use system is a combination of all land use systems found in the identification period, in a stationary way.

In view of the above, we recommend land use change modellers to check, if permitted by data availability, whether or not the system was stationary in the past and if potential causes can be found for detected non-stationarity. The methodology proposed in this paper can be used for such an analysis although it certainly needs further evaluation given the limitations of this study described above. Non-stationarity in land use change projections is challenging to model, because it is difficult to determine when the system will change and how. We cannot expect land use change modellers to incorporate systemic changes in their models. Nonetheless, we believe that they should be more aware, and communicate more clearly, that what they try to project is at the limits, and perhaps beyond the limits, of what is still projectable, because systemic changes seem to occur in reality.

\section{Acknowledgements}

This work was carried out within the BE-Basic R\&D Program, which was granted a FES subsidy from the Dutch Ministry of Economic affairs, agriculture and innovation (EL\&I). We thank the Brazilian National Institute for Space Research (INPE), and especially Bernardo Rudorff, for providing the Canasat maps that were used as observational data. Six anonymous reviewers and the special issue editors are thanked for their contributions.

\section{Appendix A. Supplementary data}

Supplementary data related to this article can be found at http:// dx.doi.org/10.1016/j.envsoft.2015.02.013.

\section{References}

Adami, M., Mello, M.P., Aguiar, D.A., Rudorff, B.FT, de Souza, A.F., 2012a. A web platform development to perform thematic accuracy assessment of sugarcane mapping in South-Central Brazil. Remote Sens. 4, 3201-3214.

Adami, M., Rudorff, B.F.T., Freitas, R., Aguiar, D.A., Sugawara, L.M., Mello, M.P., 2012b. Remote sensing time series to evaluate direct land use change of recent expanded sugarcane crop in Brazil. Sustainability 4, 574-585.

Aerts, J.C.J.H., Goodchild, M.F., Heuvelink, G.B.M., 2003. Accounting for spatial uncertainty in optimization with spatial decision support systems. Trans. GIS 7, $211-230$.

Aguiar, D.A., Personal communication, July 17th 2014.

Aguiar, D.A., da Silva, W.F., Rudorff, B.F.T., Adami, M., 2010. Canasat project: monitoring the sugarcane harvest type in the state of São Paulo, Brazil. In: Wagner, W., Székely, B. (Eds.), Procedeedings of the International Archives of the Photogrammetry, Remote Sensing and Spatial Information Sciences (ISPRS) TC VII Symposium - 100 Years, July 5-7, 2010 ed. ISPRS, Vienna, Austria, pp. $10-15$

Aguiar, D.A., Rudorff, B.F.T., Silva, W.F., Adami, M., Mello, M.P., 2011. Remote sensing images in support of environmental protocol: monitoring the sugarcane harvest in São Paulo State, Brazil. Remote Sens. 3, 2682-2703.

Aljoufie, M., Zuidgeest, M., Brussel, M., van Vliet, J., van Maarseveen, M., 2013. A cellular automata-based land use and transport interaction model applied to Jeddah, Saudi Arabia. Landsc. Urban Plan. 112, 89-99.

Aspinall, R., 2004. Modelling land use change with generalized linear models - a multi-model analysis of change between 1860 and 2000 in Gallatin Valley, Montana. J. Environ. Manag. 72, 91-103.

Bakker, M., Veldkamp, A., 2012. Changing relationships between land use and environmental characteristics and their consequences for spatially explicit land-use change prediction. J. Land Use Sci. 7, 407-424.

Bakker, M.M., Hatna, E., Kuhlman, T., Mücher, C.A., 2011. Changing environmental characteristics of European cropland. Agric. Syst. 104, 522-532.

Brown, D.G., Robinson, D.T., An, L., Nassauer, J.I., Zellner, M., Rand, W., Riolo, R., Page, S.E., Low, B., Wang, Z., 2008. Exurbia from the bottom-up: confronting empirical challenges to characterizing a complex system. Geoforum 39, 805-818.

Carlson, K.M., Curran, L.M., Ratnasari, D., Pittman, A.M., Soares-Filho, B.S., Asner, G.P., Trigg, S.N., Gaveau, D.A., Lawrence, D., Rodrigues, H.O., 2012. Committed carbon emissions, deforestation, and community land conversion from oil palm plantation expansion in West Kalimantan, Indonesia. Proc. Natl. Acad. Sci. U. S. A. 109, 7559-7564.

Claessens, L., Schoorl, J.M., Verburg, P.H., Geraedts, L., Veldkamp, A., 2009. Modelling interactions and feedback mechanisms between land use change and landscape processes. Agric. Ecosyst. Environ. 129, 157-170.

Clarke, K.C., Hoppen, S., Gaydos, L.J., 1997. A self-modifying cellular automaton model of historical urbanization in the San Francisco Bay area. Environ. Plan. B Plan. Des. 24, 247-261.

Costa, P.A.L., Gray, K., 2011. Brazilian Senate Approves New Forest Code - New Law Guarantees Preservation of $80 \%$ of the Amazon Rainforest.

de Souza Soler, L., Verburg, P.H., 2010. Combining remote sensing and household level data for regional scale analysis of land cover change in the Brazilian Amazon. Reg. Environ. Change 10, 371-386.

Efron, B., Tibshirani, R.J., 2003. An Introduction to the Bootstrap. CRC Press LLC, Boca Raton, Florida.

Farr, T.G., Rosen, P.A., Caro, E., Crippen, R., Duren, R., Hensley, S., Kobrick, M., Paller, M., Rodriguez, E., Roth, L., Seal, D., Shaffer, S., Shimada, J., Umland, J., Werner, M., Oskin, M., Burbank, D., Alsdorf, D., 2007. The shuttle radar topography mission. Rev. Geophys. 45.

Filatova, T., Polhill, J.G., 2012. Shocks in coupled socio-ecological systems: what are they and how can we model them? In: Seppelt, R., Voinov, A.A., Lange, S. Bankamp, D. (Eds.), International Environmental Modelling and Software Society (iEMSs), 2012 International Congress on Environmental Modelling and Software, Managing Resources of a Limited Planet: Pathways and Visions under Uncertainty, Sixth Biennial Meeting, Leipzig, Germany July 1-5, 2012, pp. 2619-2630.

Gallardo, A.L.C.F., Bond, A., 2011. Capturing the implications of land use change in Brazil through environmental assessment: time for a strategic approach? Environ. Impact Assess. Rev. 31, 261-270.

Gómez Jr., C., 2013. Rise of Ethanol in Brazil? SciTechDaily.

Grazzini, J., 2012. Analysis of the Emergent properties: stationarity and Ergodicity. J. Artif. Soc. Soc. Simul. 15. March 122013.

ICONE, 2012. ICONE - Institute for International Trade Negotiations, Brief Description for the Brazilian Land Use Model - BLUM. 2012.

Karssenberg, D., Schmitz, O., Salamon, P., de Jong, K., Bierkens, M.F.P., 2010. A software framework for construction of process-based stochastic spatiotemporal models and data assimilation. Environ. Model. Softw. 25, 489-502. 
Lanzante, J.R., 1996. Resistant, robust and non-parametric techniques for the analysis of climate data: theory and examples, including applications to historical radiosonde station data. Int. J. Climatol. 16, 1197-1226.

Lapola, D.M., Schaldach, R., Alcamo, J., Bondeau, A., Koch, J., Koelking, C., Priess, J.A., 2010. Indirect land-use changes can overcome carbon savings from biofuels in Brazil. Proc. Natl. Acad. Sci. U. S. A. 107, 3388-3393.

Cerqueira Leite, R.C.d., Verde Leal, M.R.L., Barbosa Cortez, L.A., Griffin, W.M., Gaya Scandiffio, M.I., 2009. Can Brazil replace 5\% of the 2025 gasoline world demand with ethanol? Energy 34, 655-661.

Lillesand, T.M., Kiefer, R.W., Chipman, J.W., 2003. Remote Sensing and Image Interpretation, fifth ed. Wiley.

Lucon, O., Goldemberg, J., 2010. São Paulo - the "other" Brazil: different pathways on climate change for state and federal governments. J. Environ. Dev. 19, 335-357.

Macedo, I.C., 2007. Sugar Cane's Energy - Twelve Studies on Brasilian Sugar Cane Agribusiness and its Sustainability.

Macedo, I.C., Seabra, J.E.A., 2008. Mitigation of GHG emissions using sugarcane bioethanol (Chapter 4). In: Zuurbier, P., van de Vooren, J. (Eds.), Sugarcane Ethanol: Contributions to Climate Change Mitigation and the Environment. Wageningen Academic Publishers, Wageningen, The Netherlands, pp. 95-110.

Manson, S.M., 2007. Challenges in evaluating models of geographic complexity. Environ. Plan. B Plan. Des. 34, 245-260.

Merz, R., Parajka, J., Blöschl, G., 2011. Time stability of catchment model parameters: implications for climate impact analyses. Water Resour. Res. 47.

Nassar, A.M., Rudorff, B.F.T., Antoniazzi, L.B., Aguiar, D.A., Bacchi, M.R.P., Adami, M., 2008. Prospects of the sugarcane expansion in Brazil: impacts on direct and indirect land use changes (Chapter 3). In: Zuurbier, P., van de Vooren, J. (Eds.), Sugarcane Ethanol: Contributions to Climate Change Mitigation and the Environment. Wageningen Academic Publishers, Wageningen, pp. 63-112.

Padua Junior, A.L., Costa Pasini, A.C., Comatsu, C.E., Casarin, D.C.P., Michelino, G.G., von Glhen, H.C., da Silva, I.X., de Moreas, J.F.L., de Carvalho, J.P., Sandoval, M., Valeriano, M., Araujo, N., Brunini, O., Vedovelo, R., Viegas, R., Campaign, R.C.F., Adami, S.F., 2012. Agro-environmental Zoning - Green Ethanol - Environmental System for São Paulo - Government of São Paulo. 2012.

Parker, D.C., Hessl, A., Davis, S.C., 2008. Complexity, land-use modeling, and the human dimension: fundamental challenges for mapping unknown outcome spaces. Geoforum 39, 789-804.

Picoli, M., 2013. Brazilian Sugarcane Mills Map - 2013.

Pijanowski, B.C., Brown, D.G., Shellito, B.A., Manik, G.A., 2002. Using neural networks and GIS to forecast land use changes: a Land Transformation Model. Comput. Environ. Urban Syst. 26, 553-575.

Pontius Jr., R.G., Neeti, N., 2010. Uncertainty in the difference between maps of future land change scenarios. Sustain. Sci. 5, 39-50.

Pontius Jr., R.G., Spencer, J., 2005. Uncertainty in extrapolations of predictive landchange models. Environ. Plan. B Plan. Des. 32, 211-230.
Rudorff, B.F.T., Aguiar, D.A., Silva, W.F., Sugawara, L.M., Adami, M., Moreira, M.A. 2010. Studies on the rapid expansion of sugarcane for ethanol production in São Paulo State (Brazil) using Landsat Data. Remote Sens. 2, 1057-1076.

Schaldach, R., Alcamo, J., Koch, J., Kölking, C., Lapola, D.M., Schüngel, J., Priess, J.A. 2011. An integrated approach to modelling land-use change on continental and global scales. Environ. Model. Softw. 26, 1041-1051.

Sparovek, G., Berndes, G., Egeskog, A., de Freitas, F.L.M., Gustafsson, S., Hansson, J., 2007 Sugarcane ethanol production in Brazil: an expansion model sensitive to socioeconomic and environmental concerns. Biofuels. Bioprod. Biorefin. 1, 270-282.

Sparovek, G., Barretto, A.G.d.O.P., Berndes, G., Martins, S., Maule, R., 2009. Environmental, land-use and economic implications of Brazilian sugarcane expansion 1996-2006. Mitig. Adapt. Strategies Glob. Change 14, 285-298.

Sparovek, G., Berndes, G., Klug, I.L.F., Barretto, A.G.d.O.P., 2010. Brazilian agriculture and environmental legislation: status and future challenges. Environ. Sci. Technol. 44, 6046-6053.

Sparovek, G., Berndes, G., Barretto, A.G.d.O.P., Klug, I.L.F., 2012. The revision of the Brazilian Forest Act: increased deforestation or a historic step towards balancing agricultural development and nature conservation? Environ. Sci. Policy 16, 65-72.

Torquato, S.A., 2006. Cana-de-açúcar para indústria: o quanto vai precisar crescer Análises Indic. Agronegócio 1.

Tóth, G., Kozlowski, B., Prieler, S., Wiberg, D., 2012. Global Agro-ecological Zones (GAEZ v3.0).

van der Hilst, F., Verstegen, J.A., Karssenberg, D., Faaij, A.P.C., 2012. Spatio-temporal land use modelling to assess land availability for energy crops - illustrated for Mozambique. Glob. Change Biol. Bioenergy 4, 859-874.

van Leeuwen, P.J., 2009. Particle filtering in geophysical systems. Mon. Weather Rev. 137, 4089-4114.

Verburg, P.H., 2006. Simulating feedbacks in land use and land cover change models. Landsc. Ecol. 21, 1171-1183.

Verburg, P.H., Soepboer, W., Veldkamp, A., Limpiada, R., Espaldon, V., Mastura, S.S.A. 2002. Modeling the spatial dynamics of regional land use: the CLUE-S model. Environ. Manag. 30, 391-405.

Verstegen, J.A., Karssenberg, D., van der Hilst, F., Faaij, A.P.C., 2012. Spatio-temporal uncertainty in spatial decision support systems: a case study of changing land availability for Bioenergy crops in Mozambique. Computers. Environ. Urban Syst. 36, 30-42.

Verstegen, J.A., Karssenberg, D., van der Hilst, F., Faaij, A.P.C., 2014. Identifying a land use change cellular automaton by Bayesian data assimilation. Environ. Model. Softw. 53, 121-136.

Wald, A., Wolfowitz, J., 1940. On a test whether two samples are from the same population. Ann. Math. Statistics 11, 147-162.

Walter, A., Dolzan, P., Quilodrán, O., De Oliveira, J.G., Da Silva, C., Piacente, F., Segerstedt, A., 2011. Sustainability assessment of bio-ethanol production in Brazil considering land use change, GHG emissions and socio-economic aspects. Energy Policy 39, 5703-5716. 